\title{
Measuring Plant Level Energy Efficiency and Technical Change in the U.S. Metal-Based Durable Manufacturing Sector Using Stochastic Frontier Analysis
}

\author{
by
}

\section{Gale Boyd \\ Duke University}

Jonathan M. Lee

East Carolina University

\section{CES 16-52 November, 2016}

The research program of the Center for Economic Studies (CES) produces a wide range of economic analyses to improve the statistical programs of the U.S. Census Bureau. Many of these analyses take the form of CES research papers. The papers have not undergone the review accorded Census Bureau publications and no endorsement should be inferred. Any opinions and conclusions expressed herein are those of the author(s) and do not necessarily represent the views of the U.S. Census Bureau. All results have been reviewed to ensure that no confidential information is disclosed. Republication in whole or part must be cleared with the authors.

To obtain information about the series, see www.census.gov/ces or contact J. David Brown, Editor, Discussion Papers, U.S. Census Bureau, Center for Economic Studies 5K034A, 4600 Silver Hill Road, Washington, DC 20233, CES.Papers.List@census.gov. To subscribe to the series, please click here. 


\begin{abstract}
This study analyzes the electric and thermal energy efficiency for five different metal-based durable manufacturing industries in the United States from 1987-2012 at the 3 digit North American Industry Classification System (NAICS) level. Using confidential plant-level data on energy use and production from the quinquennial U.S. Economic Census, a stochastic frontier regression analysis (SFA) is applied in six repeated cross sections for each five year census. The SFA controls for energy prices and climate-driven energy demand (heating degree days - HDD and cooling degree days - CDD) due to differences in plant level locations, as well as 6-digit NAICS industry effects. A Malmquist index is used to decompose aggregate plant technical change in energy use into indices of efficiency and frontier (best practice) change. Own energy price elasticities range from -.7 to -1.0 , with electricity tending to have slightly higher elasticity than fuel. Mean efficiency estimates (100 percent equals best practice level) range from a low of 32 percent (thermal 334 - Computer and Electronic Products) to a high of 86 percent (electricity 332 - Fabricated Metal Products). Electric efficiency is consistently better than thermal efficiency for all NAICS. There is no clear pattern to the decomposition of aggregate technical Thermal change. In some years efficiency improvement dominates; in other years aggregate technical change is driven by improvement in best practice.
\end{abstract}

\footnotetext{
${ }^{*}$ This paper was funded by the U.S. Energy Information Administration (EIA), Office of Energy Consumption and Efficiency Analysis) while working with Leidos Inc. under contract with EIA (DE-EI0000564) and was prepared while the authors were Special Sworn Status researchers at the Triangle Research Data Center, a member of the Federal Statistical Research Data Center Network. Any opinions and conclusions expressed herein are those of the authors and do not necessarily represent the views of the U.S. Census Bureau or EIA. All results have been reviewed to ensure that no confidential information is disclosed.
} 


\section{Introduction}

A popular conceptual modeling method for energy forecasting is the stock adjustment approach. This approach is based on the notion that energy use is tied to capital stock which changes over time in response to replacement, due to depreciation, and new expansion, to account for growth. This basic framework is used widely in the demand modules for the National Energy Modeling System (NEMS) by the U.S. Energy Information Administration (EIA). The Industrial Demand Module (IDM) is one such model that employs this underlying concept (EIA 2014).

This approach considers that the unit energy consumption (UEC) can been represented as weighted average of the UEC for existing and new applications (equipment or capital stock, etc.)

$$
U E C=\lambda *\left(U E C_{\text {exsiting }}\right)+(1-\lambda) * U E C_{\text {new }}
$$

This approach shares common features with the partial adjustment model that is commonly used in econometric studies to distinguish between long run and short run price elasticities for a wide range of macro and microeconomic phenomenon, including energy. The implications of such a model, particularly when interpreted in the context of a putty-clay approach, is that once the relevant piece of capital is put into use the UEC is constant (or nearly so) over its lifetime. This implies that there would be a distribution of UEC over different pieces of equipment. Since the distribution must have a minimum, this distribution can be thought of as the distribution of energy efficiency within a sector. The difference between the average UEC and the lowest can be thought of as a measure of the "energy gap," which has been the subject of numerous studies (Jaffe and Stavins 1994, Huntington 1995, Allcott and Greenstone 2012, Boyd and Zhang 2013, Boyd and Curtis 2014, Boyd 2016).

The putty-clay notion is an empirically strong one, particularly if the unit of observation is not a piece of equipment but a manufacturing facility. A facility itself is made of many difference pieces of capital, with different lifetimes. In addition, the UEC may not be entirely embodied in the capital, but respond either positively or negatively to other inputs; maintenance, management, etc. This means that the UEC of a manufacturing facility or plant may change over time, but still within an observable distribution. The shape and position of this distribution may also change over time, either in response to technical change or other forces. The direction and magnitude is an important empirical question.

This paper estimates the distribution of energy efficiency in metal based durables (MBD) and the evolution over time in order to better understand the nature of the "energy gap" and how it interacts with technical change to drive industry level performance. This research can inform the stockadjustment based energy forecasting of MBD in the NEMS IDM. While the efficiency distribution could be estimated using Data Envelopment Analysis (DEA) estimation approaches, this study employs the stochastic frontier analysis (SFA) econometric approach. ${ }^{1}$ To measure the evolution of efficiency and technical change over time, a Malmquist index decomposition is conducted. We also examine the efficiency of new plants entering the industry, relative to continuing plants. This provides insight into another aspect of the dynamics of energy efficiency as it relates to plant vintage.

\footnotetext{
${ }^{1}$ See Murillo-Zamorano, L. (2004) for a survey of the DEA and SFA approaches.
} 
Non-public plant level micro-data from the U.S. Census Bureau is used to control for differences in local market conditions (e.g. state level policies or energy prices) or exogenous plant specific characteristics (e.g. plant size, detailed NAICS, climate, etc.). As a result, these potential confounders that can lead to differences in plant energy use are precisely measured, and are not treated as differences in energy efficiency. By conducting the analysis at the plant level the model is capable of representing the efficiency distribution at various levels of aggregation, specifically in terms of geography (e.g. Census division) and industry, without losing state and industry level detail. In the context of forecasts, many of these plant/industry characteristics (e.g. size, 6-digit NAICS) are not amenable to forecasting. As such, they are likely to be assumed constant in the future. What is important is that differences in energy use that arise from these other characteristics, such as the distribution in plant size or detailed NAICS, is not confused with energy efficiency.

We conduct a plant level analysis of each of the five 3-digit NAICS that comprise MBD (see Table 1).

Table 1: Industrial Demand Module MBD Industry Aggregation
\begin{tabular}{|l|l|l|}
\hline $\begin{array}{l}\text { IDM Industry } \\
\text { Code }\end{array}$ & Industry Description & $\begin{array}{l}\text { NAICS } \\
\text { Code }\end{array}$ \\
\hline 14 & Fabricated Metal Products & 332 \\
\hline 15 & Machinery & 333 \\
\hline 16 & Computer and Electronic Products & 334 \\
\hline 17 & Transportation equipment & 336 \\
\hline 18 & Electrical Equip., Appliances, and Component & 335 \\
\hline
\end{tabular}

Electricity and total fuel use ${ }^{2}$ are analyzed separately for each 3-digit sector, for a total of 10 sector-fuel combinations. The analysis time period includes the years 1987, 1992, 1997, 2002, 2007, and 2012; 6 time steps from the quinquennial Census of Manufactures (CMF).

The focus is to obtain measures of the frontier (or "best practice") energy intensity and the underlying distribution in plant level energy efficiency relative to the estimated frontier, over time. The SFA has the advantage that the estimated model parameters can be used by EIA for forecasting, while the DEA approach would only provide the plant level efficiency estimates. SFA allows the analysis to directly control for a variety of effects, such as plant size, labor intensity, detailed NAICS, etc. as described below. The SFA approach is also better suited to Census disclosure requirements.

This paper is organized as follows. A brief literature review of frontier methods as applied to energy efficiency, in particular manufacturing, is presented. Next we describe the sources for the data. A modeling section describes the general approach, a brief overview of the Malmquist decomposition, and the final version of the models we estimate. The results section includes parameter estimates for the year 2012, the Malmquist estimates over the 25 year time period, and some panel models with year, region and state fixed effects.

\footnotetext{
${ }^{2}$ For simplicity fuels will be treated as all Natural Gas, with other fuel use treated as de minimis. The detailed implementation is described below.
} 


\section{Literature review}

This paper draws on the theoretical and applied literature on measuring efficiency. For a broad review see (Murillo-Zamorano 2004). The relationship between the "traditional" energy efficiency literature and the literature on productivity measurement was first discussed by (Huntington 1995). While we focus on the SFA approach applied to energy efficiency measurement, the DEA approach has also been applied to manufacturing energy efficiency. One of the earliest papers applied DEA to energy efficiency in buildings (Ferrier and Hirschberg 1992). (Boyd, Karlson et al. 1993) and (Boyd and Pang 2000) use DEA to compute a production efficiency and relate it to energy efficiency in steel and paper mills, respectively. (Mukherjee 2008) apply DEA to aggregate time series data. (Zhang, Lundgren et al. 2016) apply DEA to firm level manufacturing data in Sweden to examine the impact of the carbon emissions trading scheme in the European Union. For a broader review of energy and environmental application of DEA see (Zhou, Ang et al. 2008).

The SFA approach used here falls within the general class of problems of non-radial, input specific efficiency measures (Filippini and Hunt 2015) which describes three similar approaches. The first two measure technical efficiency via the factor requirements function (Boyd 2005, Boyd, Dutrow et al. 2008, Boyd 2008, Boyd 2014) which is shown by (Boyd 2008) to equivalent to a directional distance function (Zhou, Ang et al. 2012). The third expands the notion of efficiency to include both allocative and technical efficiency (Filippini and Hunt 2011). This paper also expands the concept of efficiency to include allocative efficiency via introducing energy prices in an ad-hoc energy demand equation as in (Filippini and Hunt 2011, Filippini and Hunt 2012) and (Lundgren, Marklund et al. 2016). In addition, (Adetutu, Glass et al. 2016) apply SFA to OECD level data to estimate rebound effects. (Aranda-Usón, Ferreira et al. 2012) and (Feijoó, Franco et al. 2002) apply SFA to energy use in the Spanish manufacturing sector. (Lin and Long 2015) analyze the chemical sector in China using provincial level data.

\section{Representation of inefficiency}

The SFA approach to energy may be broadly represented as

$$
\ln E_{j, i, t}=f()+v_{j, i, t}+u_{j, i, t}
$$

Where

$\mathrm{j}=$ energy type (electricity and fuel)

$\mathrm{i}=$ individual observation (i.e. manufacturing plant)

$\mathrm{t}=$ time unit of the observations

The last two terms represent statistical noise, $v_{j, i, t}$, and inefficiency, $u_{j, i, t}$, respectively. There are wide number of choices to represent the inefficiency term $u_{j, i, t}$. Recent methods include Green's "true" fixed and random effects at the individual (plant) level (Greene 2005) which would separate plant specific heterogeneity (also called persistent efficiency) with some time varying component. However, it isn't clear if one should treat heterogeneity as separate from efficiency.

The approaches available for exogenous inefficiency effects (including time, industry, plant size, etc.) are numerous. One approach is implemented in the Normal-Truncated Normal model, where it is possible to compute non-monotonic effects of the exogenous factors on both the variance and location 
(truncation point) of the efficiency distribution, for example (Filippini and Hunt 2011) (Filippini and Hunt 2012). This form for representing the efficiency distribution is of particular interest in the proposed modeling of higher energy prices and other influences as putting "pressure" on plants to operate closer to the frontier. State dummy variables, representing possible region specific policy effects or climate, could also be included in this type of Normal-Truncated Normal. This approach would make energy use (efficiency) sensitive to prices, but making no attempt to differentiate between allocative and technical inefficiency.

The SFA parameters for the (in)efficiency distribution will allow for scenario analysis and possible forecasting of exogenous effects on both the frontier and the underlying efficiency. Another possibility is a non-parametric kernel density of the underlying plant level efficiency distribution(s) using a random number support points as an approximation to the estimated kernel. Census clearance rule prohibit any plant level estimates and the parameters of the kernel are based on supports in the neighborhood of each observation. The advantage would be a simple way to compute the levels of inefficiency at the quartile or decile level.

\section{Price effects}

The applied and theoretical literature on efficiency measurement includes both production and cost efficiency approaches. To apply a cost efficiency measurement approach to energy either a fully specified cost function, or a separable energy demand approach is needed. This paper is motivated by the latter. Energy prices provide the basis for the frontier cost (minimizing) level of energy demand, given output and quasi-fixed inputs. The approach used by (Lundgren, Marklund et al. 2016) is the most similar to our analysis.

When one considers how energy prices effect energy use over time, the notion of induced technical change is of key importance. In the case of induced technical change, it is possible that the frontier shifts in response to energy price shocks by the introduction of new technologies, i.e. high prices motivate the invention or commercialization of new energy efficient technologies (i.e. LED lighting). In this case, the asymmetric approach proposed by (Gately and Huntington 2002) might be appropriate, i.e. using the highest past price as an indicator of induced technical change. We would expect induced change to be a global, not local effect, so national average prices might be appropriate. On the other hand, past prices at the plant level could reflect a putty-clay form of hysteresis, where high plant level prices in the past resulted in irreversible investments. In this case, Gately and Huntington used an asymmetric price variable that distinguished between rising and falling prices.

\section{DATA}

Data for the study are non-public plant-level Census Bureau data available in the Federal Statistical Research Data Center. These data are protected under Title 13 and 26 of the U.S. Code and used with permission from the Bureau. The analysis time period includes the years 1987, 1992, 1997, 2002, 2007, and 2012; 6 time steps from the quinquennial Census of Manufactures (CMF).

Data needed for the analysis include energy use and prices along with production activities and other location specific variables. While the Manufacturing Energy Consumption Survey (MECS) provides the most detailed data on energy use, particularly cost and quantity of fuels by type, the MECS is a subsample of the Census Bureau's Annual Survey of Manufactures (ASM) that targets mainly large plants, and the presence (absence) of an observation is not an indicator of entry (exit) in the industry. We need 
this information on entry/exit/continuing status for the Malmquist decomposition and comparison of the relative efficiency of entering vs continuing plants. Using the $\mathrm{CMF}$, part of the quinquennial Economic Census (EC) solves this problem.

The availability of plant level electricity use and prices in the EC is also a major advantage of this data set. (Davis, Grim et al. 2012) analyze the dispersion of those prices in detail. However, the EC only reports cost of fuels, not quantities, so Btu fuel consumption is imputed from fuel costs in the CMF using the assumption that most fuel use in this sector is natural gas. This is a reasonable assumption for the metal based durables industries that we focus on, because publicly available MECS data from 2010 for these 5 sectors suggests that 88 to 98 percent the purchased fuel in this sector is natural gas. We impute Btu consumption by taking the cost of fuels and dividing by the state level natural gas prices as published by the EIA's State Energy Data System (SEDS). ${ }^{3}$ The CMF provides plant level electricity consumption and costs, from which a plant level price can be computed. Plant level shipment values, adjusted for inventory changes are used to measure production. Labor is measured in production worker hours. All data in \$ values are deflated using the (Bartelsman and Gray 1996) NBER 6-digit NAICS price deflators. The ZIP code location of the plant is merged with NOAA weather station data to get a plant specific heating and cooling degree day (HDD and CDD) measure as a control for the energy impact of location and time specific climate conditions. The section that follows provides an overview of the empirical models used to estimate plant-level energy efficiency using the EC data.

\section{General Modeling approach}

We estimate a SFA ad hoc energy demand equation for the two primary energy types in each of the five 3-digit NAICS that comprise this sector. The use of SFA in log form will facilitate the NEMS approach to measure relative energy intensity (2014) while controlling for scale and other effects, since the plant estimates of inefficiency, in log form, can be interpreted as percent differences from the frontier and can easily be transformed into percent differences from the mean. At a high level of abstraction, we consider models of the general form below,

$$
\begin{gathered}
\ln E_{j, i, t}=f\left(\ln Y_{i, t}, \operatorname{lnEmp}_{i, t}, P_{j, t, s}, \text { DYear }_{t}, \text { DNAICS }_{k}, \text { DState }_{S}, C D D_{i, t}, H D D_{i, t}, \% C H P_{i, t}\right) \\
+v_{j, i, t}+u_{j, i, t}
\end{gathered}
$$

Where

$\mathrm{j}=$ energy type (electricity and fuel)

$\mathrm{i}=$ individual establishment (i.e. manufacturing plant)

$t=$ year of the observations i.e. 1987, 1992, 1997, 2002, 2007, and 2012

$k=6$-digit NAICS

$\mathrm{s}=$ state

The last two terms represent statistical noise, $v_{j, i, t}$, and inefficiency, $u_{j, i, t}$, respectively. We will return to specific approaches to the distributional assumptions of $u_{j, i, t}$ below.

${ }^{3}$ SEDS data is available online at http://www.eia.gov/state/seds/ (last accessed November, 2016).

6| P a g e 
Both total value of shipments (TVS) and value added (VA) are considered in the model as measures of activity, In $Y$. VA might be preferred since it partially controls for the "make/buy" element of the materials/energy substitution at the plant level, however, our results do not indicate any statistically significant differences among models dependent upon choice of production activity. As a result, our preferred models use TVS as the dependent variable, because this is the aggregate output variable employed in NEMS for forecasting purposes. Labor, measured by InEmp, controls for plant level utilization effects, ${ }^{4}$ since labor may be sticky in the short run. The long run relationship between energy and plant scale is captured by the combined coefficient on production and labor, $\operatorname{In} Y$ and $\ln E m p$. In a simple Cobb-Douglas specification the sum of the coefficients on $\operatorname{In} Y$ and $\ln E m p$ reflect the economies of scale with respect to energy. If the sum of the coefficients is less than one then we can infer that larger plants will have lower frontier energy intensity than smaller plants. This means that the model will control for scale differences with respect to energy use directly in the plant specific frontier so that differences in plant scale (size) will not be subsumed into the energy efficiency measure.

Within a 3-digit NAICS there can be a lot of heterogeneity, so six digit NAICS industry controls are used for the primary analysis. One could consider product level dummies as well, since the CMF has such detail. However, doing so would require very specific prior information about which product level NAICS are more/less intensive, since there are a very large number of 10-digit product NAICS. Interaction of the 6-digit NAICS with continuous variable specifications, such as $\ln Y$ and $\operatorname{lnEmp}$, could be explored, sample size permitting.

$P_{j, t, s}$ reflects the price effects. The prices of both types of energy ( $\mathrm{j}=$ electricity and fuel) may impact either energy type. Variation in energy prices can be used to capture price incentives and allocative efficiency. Electricity and fuel have different data issues, so the treatment of prices will also have to be different. Census data collects plant level cost and quantity for electricity but only costs for fossil fuels. The problem with using plant level electric prices ${ }^{5}$ directly in the model is that the plant may have some bargaining power or simply more choice over rate plans, with larger electricity users realizing lower average prices, resulting in an endogenous variable. Although not reported, we considered instruments for this using either state level prices from SEDS or county level average prices constructed directly from the Census data. Our IV estimates are generally similar to the SFA results presented herein, and formal Hausman tests for endogeneity of prices generally reject the null hypothesis that plant-level prices are exogenous in the MBD sector.

Incorporating prices into the factor requirement function allows us to measure price responsiveness of the sectors. If we view the model in a production function context then higher energy prices could act as an exogenous shifter of the frontier, i.e. induced technical change.

The $D$ prefix in the energy factor requirements function given above indicates dummy variables to control for various plant characteristics. State (region) level dummies are used to capture a range of unobserved state characteristics. In particular, state dummies could capture differences in the regulatory / business environment, including state specific policies regarding energy efficiency.

\footnotetext{
${ }^{4}$ Using the 5-year Economic Census also conveniently avoids the years of the Great Recession by including 2007 and 2012, but not the intervening years.

${ }^{5}$ These prices are not true marginal prices, but include demand charges, etc. They are total expenditures divided by total consumption.

7가 P g e
} 
Heating Degree Days (HDD) and Cooling Degree Days (CDD) are used to control for ambient weather conditions on an annual basis using the zip-code location of the plant. "Weather" can impact building HVAC energy use, but also impact process energy via outside air to ovens and furnaces or chiller efficiencies, to the extent that the production requires these process. While one may expect that HDD would impact fuel use and CDD electricity use, both variables are included in each one of the energy regression equations.

Modeling electricity and fuel separately has advantages, since sector specific process needs will differ in terms of energy type. However, there may be opportunities to substitute electricity for fuel, combined heat and power being the most obvious. Since Census data does include on-site generation we can at least include a variable to control for the share of combined heat and power $(\% C H P) .{ }^{6}$ In this form the variable acts like a semi-elasticity. In the electric equation we would expect a coefficient of negative unity, but in the fuel equation the coefficient would be positive account for the amount of extra fuel consumed in the CHP. We can also, ex-post, see if there is any obvious inverse correlation between electric and fuel efficiency, which might suggest some other types of electric/fuel process switching.

\section{Primary models under consideration}

There are many models that one can consider using for estimation of efficiency and price effects on energy use in either a panel or cross-section setting. The initial focus was on several different versions of the SFA estimated in the cross-section; plant level random effects and models that combine fixed/random effects with SFA (i.e. the "true" fixed and random effects as presented by Greene 2005). After initial analysis the focus was shifted to obtaining parameter estimates and efficiency distributions from some of the simpler formulations for the SFA. In the initial stage of the analysis the panel models appear to be too computationally challenging for a data set of this size. Panel data versions of the SFA, including the normal-truncated normal models all had convergence issues, so we have focused on getting estimates from a sub-set of the available methods using year specific repeated cross sections.

The basic specification remains as above, but without the state dummies. It is not possible to use state dummies because the natural gas price is state level. The main differences arise from how the efficiency term $u_{j, i, t}$ is derived.

$$
\ln E_{j, i, t}=f\left(\ln Y_{i, t}, \operatorname{lnEmp} p_{i, t}, \text { DYear }_{t}, \operatorname{DNAICS}_{k}, P_{E, t, s}, P_{F, t, s}, x_{j} D D_{i, t} \cdots\right)+v_{j, i, t}+u_{j, i, t}
$$

The SFA approach assumes that $u_{j, i, t}$ is follows a one-sided error distribution. Exponential and halfnormal distributions, with variance $\sigma_{u_{j}}$. These are two distributions that have closed form likelihood functions and are commonly used in the SFA literature. Truncated normal and Gamma distributions require the estimation of two distributional parameters and have proven too computationally challenging for our data sets, so we focus on the simpler alternatives. The standard SFA approach ignores the panel nature of this data set, specifically the notion that the plant level efficiency term $u_{j, i, t}$ is likely correlated over time, violating the assumption used in the cross sectional SFA. Rather than

\footnotetext{
${ }^{6} \mathrm{CHP}$ in MBD is expected to be a very small percent of the plants. This variable was excluded in the results presented below since the number of non-zero observations were so small they would have presented disclosure issues. EIA Forms 860 and 923 have capacity and generation to the plant level for grid connected plants greater than $1 \mathrm{MW}$. These data are identified by company and latitude/longitude. These data may help further identify CHP for other sectors, e.g. bulk chemicals.
} 
impose additional parameters to be estimated in the panel SFA approaches we choose to take advantage of the large number of plants in each year of the data and use a cross sectional approach for each 5 year period. We also note that there is a substantial amount of entry and exit in these industries, so our data set is unbalanced, which poses additional challenges related to the calculation of our Malmquist Indices measuring technical change. We use the repeated cross sections and also examine these model for stability of the elasticities and efficiency distributions over time ${ }^{7}$.

To obtain an estimate of inefficiency we first take the estimate of the residual from the model

$$
\widehat{\varepsilon_{j, l, t}}=v_{j, i, t}+u_{j, i, t}=\ln E_{j, i, t}-f\left(\ln Y_{i, t}, \ln E m p_{i, t}, D N A I C S_{k}, P_{E, t, s}, P_{F, t, s}, \% C H P_{i, t}, x_{j} D D_{i, t} \ldots\right)
$$

Using standard methods developed in the SFA literature we compute the parameters for the function $f()$ and the expectation of the efficiency component conditional on the residuals, using the mean or mode, and convert to a measure of inefficiency see (Murillo-Zamorano 2004).

$$
\begin{gathered}
\widehat{u_{, l, t}}=\boldsymbol{E}\left(u_{j, i, t} \mid \widehat{\varepsilon_{j, l, t}}\right) \text { or } \boldsymbol{M}\left(u_{j, i, t} \mid \widehat{\varepsilon_{j, l, t}}\right) \\
E f f_{j, i, t}^{S F, m}=e^{-\widehat{u_{j, l, t}}}
\end{gathered}
$$

\section{Measuring technical change}

The general approach for measuring technical change is based on the Malmquist index. Following (Färe and Grosskopf 1992), to define the Malmquist index we must first define the input distance function.

$$
D_{i}^{t}\left(y^{t}, x^{t}\right)=\sup \left\{\lambda>0:\left(\frac{x^{t}}{\lambda}\right) \epsilon L^{t}\left(y^{t}\right)\right\}
$$

Where $L^{t}\left(y^{t}\right)$ is the input correspondence of the production technology set

$$
S^{t}=\left\{\left(y^{t}, x^{t}\right): x^{t} \text { can produce } y^{t}\right\} .
$$

The input correspondence follows the basic production axioms outlined in (Färe and Grosskopf 1992). The distance function is the largest scalar value, $\lambda$, by which we can reduce the input vector, $x^{t}$, and still produce the output vector, $y^{t}$.

The Malmquist index of aggregate change between $t=1$ and $t=0$ is defined as

$$
M_{i}^{1}\left(y^{1}, x^{1}, y^{0}, x^{0}\right)=\left[\frac{D_{i}^{0}\left(y^{1}, x^{1}\right)}{D_{i}^{0}\left(y^{0}, x^{0}\right)} \frac{D_{i}^{1}\left(y^{1}, x^{1}\right)}{D_{i}^{1}\left(y^{0}, x^{0}\right)}\right]^{\frac{1}{2}}
$$

Not that the Malmquist index requires two distance functions defined over each time period. We can decompose this index of aggregate change into two components, efficiency change and frontier technical change. First, we define the Malmquist index of efficiency change as

$$
M E_{i}^{1}\left(y^{1}, x^{1}, y^{0}, x^{0}\right)=\frac{D_{i}^{1}\left(y^{1}, x^{1}\right)}{D_{i}^{0}\left(y^{0}, x^{0}\right)}
$$

\footnotetext{
${ }^{7}$ We retain the time subscript in the notation since we will get estimates for each time period, but not from a panel approach, per se.
}

9| P a g e 
One can think of efficiency change as "observable" progress - where the firm/plant is now given today's output vs where the firm/plant was last period given last period's output. Given this notion of efficiency change the measure of frontier technical change (here after just technical change) can be derived

algebraically as $\operatorname{MT}_{i}^{1}\left(y^{1}, x^{1}, y^{0}, x^{0}\right)=\left[\left.\frac{D_{i}^{0}\left(y^{1}, x^{1}\right)}{D_{i}^{1}\left(y^{1}, x^{1}\right)} \frac{D_{i}^{0}\left(y^{0}, x^{0}\right)}{D_{i}^{1}\left(y^{0}, x^{0}\right)}\right|^{\frac{1}{2}}\right.$

Such that

$$
M_{i}^{1}=M E_{i}^{1} \cdot M T_{i}^{1}
$$

Empirically the distance functions are often computed using DEA, but can also be computed using estimates from the stochastic frontier (Coelli, Rao et al. 2005).

$$
D_{i}^{t}\left(y^{t}, x^{t}\right)=E f f_{j, i, t}^{S F, m}=e^{-\widehat{u_{j, l, t}}}
$$

However, we are interested, not in the distance function defined over the entire vector of inputs, but on the energy sub-vector (directional) distance function as defined by (Boyd 2008). In addition, the interpretation of the directional distance function used by (Boyd 2008) needs to be modified in this context, due to the inclusion of prices in the efficiency measure and resulting distance. Consider the difference between the standard Shepard input distance function as shown in Figure 1 and defined by the line AB. The sub-vector (energy directional) distance function used by (Boyd 2008) is defined by the line AC. Now consider the case shown in Figure 2 where the isoquant and the cost minimizing input combinations are shown for two different sets of energy prices. The relevant direction for the distance function is either $A D^{\prime}$ or $A D^{\prime \prime}$, depending on the energy prices. At higher energy prices the relative efficiency of point $A$ would be $E-E_{2} *<E-E_{1}{ }^{*}$. In the DEA formulation of the distance function one would need to specify the direction vector, but in the case of the SFA approach the inclusion of energy prices make the optimal direction implicit in the computed measure of efficiency. 


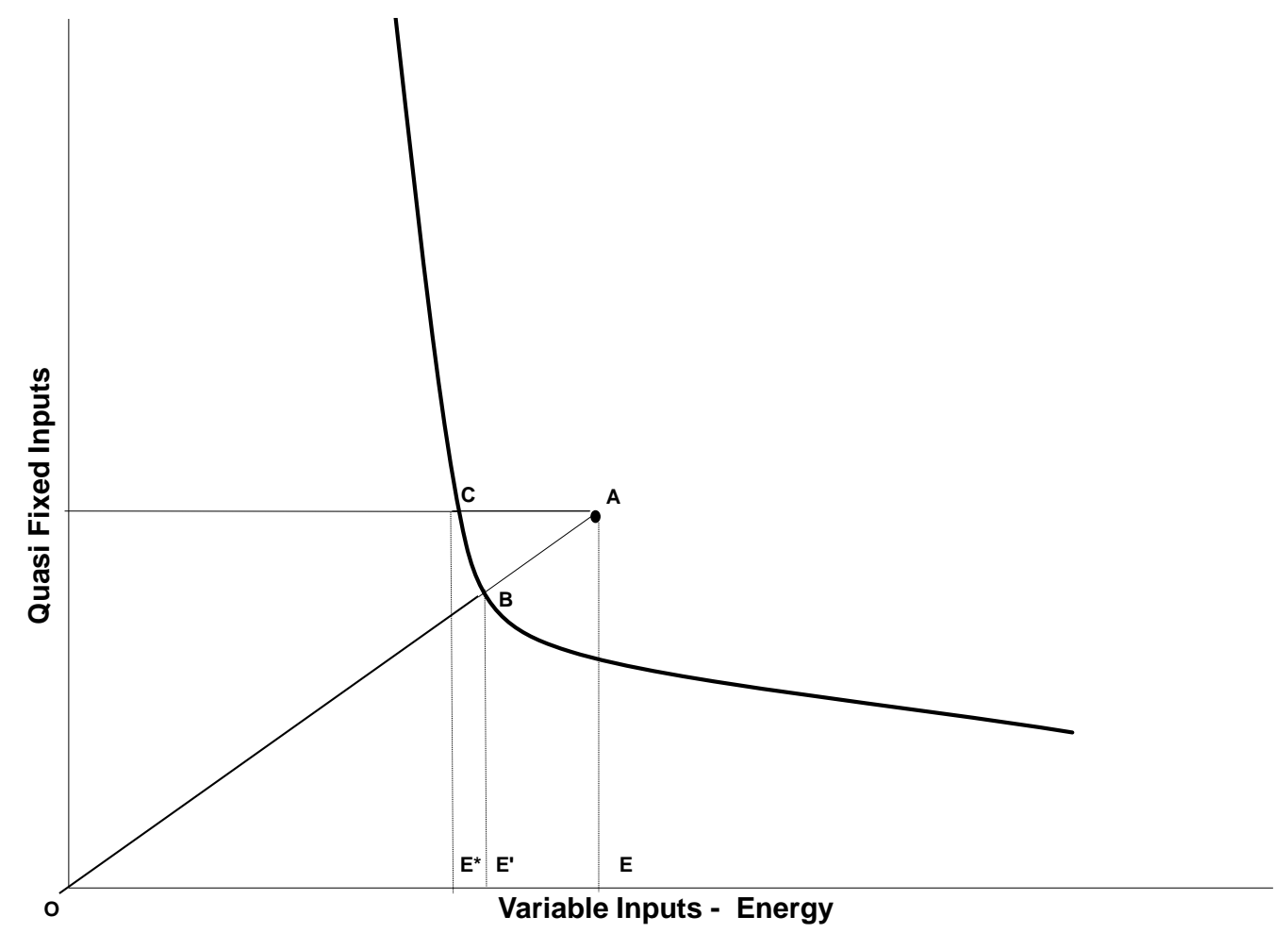

Figure 1 Comparison of the Standard input distance function and the sub-vector distance function

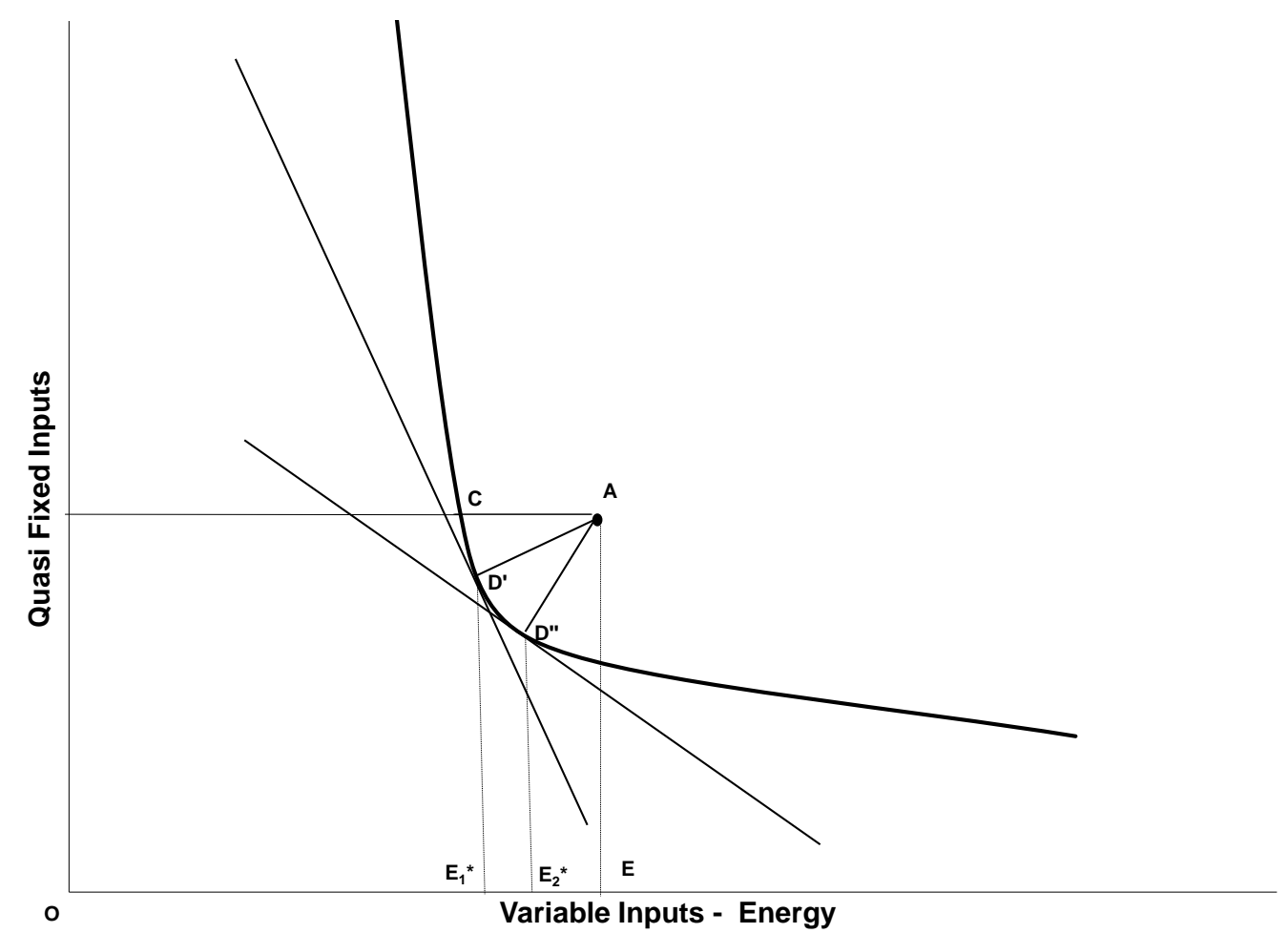

Figure 2 Comparison of Optimal Price Direction Distance Functions

11| P a g e 


\section{RESULTS}

The results presented here are based on a repeated cross section estimation for each of the quinquennial EC years as described above. In addition, a pooled analysis was performed that assumes the concerns about time series correlation at the plant level is minimal, given the 5-year times steps. These panel results are not our preferred models, but are presented to provide an alternative view of technical change vis-à-vis the Malmquist analysis on the repeated cross sections.

Despite the attractive nature of a panel data analysis with time varying efficiency and plant level heterogeneity all the panel model specifications attempting to control for unobserved time invariant plant heterogeneity failed to converge. The problem of the fixed and random effect estimation approach when the number of establishment is very large relative to the number of time periods is well established. The panels suffered from the problem of large numbers of establishments (ranging from a few thousand to over 20 thousand depending on the NAICS) and a small number of time periods (6 five year increments). This is complicated by the large amount of entry and exit in these industries, so that in practice almost no plants are in the data for all six of the years included in the analysis.

One might argue that the five year time step is sufficiently long to assume that the error terms are uncorrelated and simply pool the entire sample and ignore the panel aspect of the data. We present some results based on that simplifying assumption in order to examine time fixed effects. On the other hand, since the number of establishments is fairly large we exploit the cross-sectional variation in each year to estimate a NAICS and year specific model as the basis for the estimates of energy efficiency.

A slightly simplified version of the more general panel model is estimated for each energy type, 3-digit NAICS and year.

$$
\begin{gathered}
\ln E_{j, K, t, i}=\alpha+\beta_{j, K, t}^{y} \ln Y_{i, t}+\beta_{j, K, t}^{E m p} \ln E m p_{i, t}+\gamma_{j, K, t}^{E} \ln P_{E, t, i}+\gamma_{j, K, t}^{F} \ln P_{F, t, s}+\delta_{j, K, t}^{C D D} \ln C D D_{i, t} \\
+\delta_{j, K, t}^{H D D} \ln H D D_{i, t}+\sum_{k \in K} \alpha_{k} D N A I C S_{k}+v_{j, K, i, t}+u_{j, K, i, t}
\end{gathered}
$$

Where

$j=E, F$, the type energy (electricity and fuel respectively)

$t=$ year of the observations i.e. 1987, 1992, 1997, 2002, 2007, and 2012

$\mathrm{i}=$ individual establishment (i.e. manufacturing plant)

$s=$ state location for the individual establishment (i.e. manufacturing plant)

$\mathrm{K}=$ one of the 53 digit NAICS comprising MBD

$\mathrm{k}=$ a 6 digit NAICS associated with the Kth 3-digit NAICS ${ }^{8}$

The last two terms represent statistical noise, $v_{j, i, t}$, and inefficiency, $u_{j, i, t}$, respectively. Half normal and exponential distributional assumptions for $u_{j, i, t}$ were used and are also compared to OLS parameter estimates.

${ }^{8}$ 6-digit NAICS parameter estimates were not requested to be cleared by Census; many of these industry fixed effects are significant based on simple t-tests.

12| P a g e 
Parameter estimates for 2012 are presented in Tables 1-5 for each of the 3-digit MBD NAICS. The parameter estimates are fairly stable over time; 2012 results are felt to be generally representative and most relevant to forecasting, regardless. SFA results under the half-normal and exponential distribution are presented along with the OLS for comparison purposes. All p-values are based on robust standard errors. Iteration counts above 20 generally indicate models that fail to converge resulting in estimates that are almost identical to OLS and with no estimates of efficiency.

Table 1 NAICS 332 Estimates for 2012

\begin{tabular}{|c|c|c|c|c|c|c|}
\hline \multirow{2}{*}{ VARIABLES } & & & & & & \\
\hline & $\begin{array}{c}\text { OLS } \\
\text { Electricity }\end{array}$ & $\begin{array}{l}\text { Half Normal } \\
\text { Electricity }\end{array}$ & $\begin{array}{l}\text { Exponential } \\
\text { Electricity }\end{array}$ & $\begin{array}{l}\text { OLS } \\
\text { Fuel }\end{array}$ & $\begin{array}{l}\text { Half Normal } \\
\text { Fuel }\end{array}$ & $\begin{array}{c}\text { Exponential } \\
\text { Fuel }\end{array}$ \\
\hline $\ln Y$ & $0.630^{\star \star \star}$ & $0.630 * \star \star$ & $0.632^{\star \star \star}$ & $0.500^{\star \star *}$ & $0.479^{\star \star \star}$ & $0.488^{\star \star \star}$ \\
\hline $\ln E m p$ & $0.489 * * \star$ & $0.489 * * \star$ & $0.490^{\star * *}$ & $0.453^{\star \star *}$ & $0.429 * * \star$ & $0.432^{\star * \star}$ \\
\hline $\ln P_{E}$ & -0.739 *** & $-0.739 * \star \star *$ & -0.729 *** & -0.00225 & -0.00294 & 0.00962 \\
\hline $\ln P_{F}$ & -0.00714 & -0.00714 & -0.00757 & $-0.833^{\star \star \star}$ & $-0.840^{* * *}$ & $-0.841^{\star \star *}$ \\
\hline $\ln H D D$ & $0.0891^{* * *}$ & $0.0891^{\star \star *}$ & $0.0885^{* * *}$ & $0.144^{* \star *}$ & $0.138^{\star \star \star}$ & $0.143^{\star \star *}$ \\
\hline $\ln C D D$ & $0.0643^{\star * *}$ & $0.0643^{\star * *}$ & $0.0634^{\star * *}$ & $0.0419^{\star \star *}$ & $0.0349 * *$ & $0.0347^{\star *}$ \\
\hline Constant & $-1.308^{\star \star \star}$ & $-1.527^{\star \star \star}$ & $-1.740^{* * *}$ & $2.920^{\star \star \star}$ & $1.242^{\star \star \star}$ & $1.453^{\star * *}$ \\
\hline $\ln \sigma_{u}^{2}$ & & $-13.36^{\star \star \star}$ & $-2.989^{\star \star \star}$ & & $0.566^{\star \star \star}$ & $-0.597^{\star \star \star}$ \\
\hline $\ln \sigma_{v}^{2}$ & & $-0.699 * \star \star$ & $-0.814^{\star \star \star}$ & & $-0.751^{\star \star \star}$ & $-0.518^{\star \star \star}$ \\
\hline Returns to scale & 1.119 & 1.119 & 1.122 & 0.953 & 0.908 & 0.92 \\
\hline Observations & 23063 & 23063 & 23063 & 23063 & 23063 & 23063 \\
\hline R-squared & 0.82 & & & 0.624 & & \\
\hline Iteration Count & & 47 & 7 & & 8 & 6 \\
\hline $\begin{array}{c}* \star \star p<0.01,{ }^{\star *} p<0.05 \\
{ }^{\star} p<0.1\end{array}$ & & & & & & \\
\hline mean efficiency & & NA & $80 \%$ & & $35 \%$ & $48 \%$ \\
\hline median efficiency & & NA & $86 \%$ & & $41 \%$ & $60 \%$ \\
\hline$\sigma_{u}$ & & 0.0012 & 0.2243 & & 1.32710 & 0.7419 \\
\hline$\sigma_{v}$ & & 0.7050 & 0.6656 & & 0.6869 & 0.7718 \\
\hline$\sigma_{u} / \sigma_{v}$ & & 0.0017 & 0.3370 & & 1.9318 & 0.9612 \\
\hline
\end{tabular}




\begin{tabular}{|c|c|c|c|c|c|c|}
\hline \multirow[b]{2}{*}{ VARIABLES } & \multicolumn{3}{|c|}{ Half } & \multicolumn{3}{|c|}{ Half } \\
\hline & $\begin{array}{c}\text { OLS } \\
\text { Electricity }\end{array}$ & $\begin{array}{l}\text { Normal } \\
\text { Electricity }\end{array}$ & $\begin{array}{l}\text { Exponential } \\
\text { Electricity }\end{array}$ & $\begin{array}{l}\text { OLS } \\
\text { Fuel }\end{array}$ & $\begin{array}{l}\text { Normal } \\
\text { Fuel }\end{array}$ & $\begin{array}{c}\text { Exponential } \\
\text { Fuel }\end{array}$ \\
\hline $\ln Y$ & $0.501^{\star \star \star}$ & $0.513^{\star \star \star}$ & $0.524^{\star \star \star}$ & $0.397^{\star \star \star}$ & $0.410^{\star \star \star}$ & $0.410 * \star \star$ \\
\hline $\operatorname{lnEmp}$ & 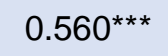 & 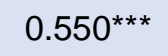 & $0.541^{\star \star \star}$ & $0.501^{\star * \star}$ & $0.452^{\star \star \star}$ & $0.466^{\star \star \star}$ \\
\hline $\ln P_{E}$ & $-0.833^{\star \star *}$ & $-0.820^{\star \star *}$ & $-0.805^{\star \star \star}$ & $0.0842^{\star *}$ & -0.0616 & -0.0575 \\
\hline $\ln P_{F}$ & $-0.0677^{\star *}$ & $-0.0699 * *$ & $-0.0739 \star \star \star$ & $-0.906^{\star \star \star}$ & $-0.914^{\star \star \star}$ & $-0.915^{\star \star \star}$ \\
\hline $\ln H D D$ & $0.0522^{* \star *}$ & $0.0552^{\star \star *}$ & $0.0613^{\star \star \star}$ & $0.128^{\star * *}$ & $0.148^{\star \star \star}$ & $0.159 * \star \star$ \\
\hline $\ln C D D$ & $0.0484^{\star \star *}$ & $0.0499 * * \star$ & $0.0531^{\star \star \star}$ & -0.00693 & -0.00486 & -0.00221 \\
\hline Constant & $-0.691^{\star *}$ & $-1.086^{\star \star \star}$ & $-1.078^{\star \star \star}$ & $2.888^{\star \star \star}$ & $1.516^{\star \star \star}$ & $1.702^{\star \star \star}$ \\
\hline $\ln \sigma_{u}^{2}$ & & $-0.946^{\star \star *}$ & $-1.984^{\star \star \star}$ & & $0.636^{\star \star *}$ & $-0.532^{\star \star \star}$ \\
\hline $\ln \sigma_{v}^{2}$ & & $-1.045^{\star \star *}$ & $-1.049^{\star \star \star}$ & & $-0.876^{\star \star *}$ & $-0.597^{\star \star \star}$ \\
\hline Returns to scale & 1.061 & 1.063 & 1.065 & 0.898 & 0.862 & 0.876 \\
\hline Observations & 9987 & 9987 & 9987 & 9987 & 9987 & 9987 \\
\hline R-squared & 0.808 & & & 0.617 & & \\
\hline Iteration Count & & 10 & 7 & & 7 & 5 \\
\hline \multicolumn{7}{|c|}{$\begin{array}{c}{ }^{* * *} p<0.01,{ }^{* *} p<0.05 \\
{ }^{*} p<0.1\end{array}$} \\
\hline mean efficiency & & $61 \%$ & $69 \%$ & & $33 \%$ & $46 \%$ \\
\hline median efficiency & & $66 \%$ & $77 \%$ & & $40 \%$ & $59 \%$ \\
\hline$\sigma_{u}$ & & 0.6250 & 0.3708 & & 1.3743 & 0.7664 \\
\hline$\sigma_{v}$ & & 0.5930 & 0.5918 & & 0.6453 & 0.7419 \\
\hline$\sigma_{u} / \sigma_{v}$ & & 1.0539 & 0.6265 & & 2.1297 & 1.0330 \\
\hline
\end{tabular}




\begin{tabular}{|c|c|c|c|c|c|c|}
\hline VARIABLES & $\begin{array}{c}\text { OLS } \\
\text { Electricity }\end{array}$ & $\begin{array}{c}\text { Half } \\
\text { Normal } \\
\text { Electricity }\end{array}$ & $\begin{array}{c}\text { Exponential } \\
\text { Electricity }\end{array}$ & $\begin{array}{l}\text { OLS } \\
\text { Fuel }\end{array}$ & $\begin{array}{l}\text { Half Normal } \\
\text { Fuel }\end{array}$ & $\begin{array}{c}\text { Exponential } \\
\text { Fuel }\end{array}$ \\
\hline $\ln Y$ & 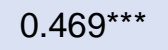 & $0.475^{\star \star \star}$ & $0.477^{\star \star *}$ & $0.294^{\star \star \star}$ & $0.293^{\star \star \star}$ & $0.277^{\star \star \star}$ \\
\hline $\ln E m p$ & $0.594^{\star \star \star}$ & $0.588^{\star \star \star}$ & $0.588^{\star \star \star}$ & $0.520 * \star \star$ & $0.485^{\star \star \star}$ & $0.509 * * *$ \\
\hline $\ln P_{E}$ & $-0.977^{\star \star *}$ & $-0.962^{\star \star \star}$ & $-0.952^{\star \star *}$ & $-0.376^{\star \star \star}$ & $-0.314^{\star \star *}$ & $-0.307^{\star \star \star}$ \\
\hline $\ln P_{F}$ & $0.120^{\star \star}$ & $0.113^{\star \star}$ & $0.105^{\star \star}$ & $-0.709 * \star \star$ & $-0.713^{\star \star *}$ & $-0.718^{\star \star \star}$ \\
\hline $\ln H D D$ & 0.0145 & 0.0118 & 0.0109 & $0.151^{\star \star \star}$ & $0.174^{\star \star \star}$ & $0.180^{\star \star \star}$ \\
\hline $\ln C D D$ & $0.0499 * *$ & $0.0483^{\star \star}$ & $0.0473^{\star *}$ & 0.0567 & 0.0502 & 0.0482 \\
\hline Constant & 0.0478 & $-1.207^{\star \star \star}$ & $-1.072^{\star \star \star}$ & $2.528^{\star \star \star}$ & 0.465 & $0.818^{*}$ \\
\hline $\ln \sigma_{u}^{2}$ & & 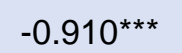 & $-1.928^{\star \star \star}$ & & $0.713^{\star \star \star}$ & $-0.448 * * *$ \\
\hline $\ln \sigma_{v}^{2}$ & & $-0.920^{\star * \star}$ & $-0.920 * \star \star *$ & & $-0.775^{\star \star \star}$ & $-0.518^{\star \star \star}$ \\
\hline Returns to scale & 1.063 & 1.063 & 1.065 & 0.814 & 0.778 & 0.786 \\
\hline Observations & 3409 & 3409 & 3409 & 3409 & 3409 & 3409 \\
\hline R-squared & 0.838 & & & 0.582 & & \\
\hline Iteration Count & & 12 & 7 & & 7 & 6 \\
\hline $\begin{array}{c}* * * p<0.01, * * \\
p<0.05 \\
* p<0.1\end{array}$ & & & & & & \\
\hline mean efficiency & & $60 \%$ & $68 \%$ & & $32 \%$ & $45 \%$ \\
\hline median efficiency & & $65 \%$ & $77 \%$ & & $38 \%$ & $57 \%$ \\
\hline$\sigma_{u}$ & & 0.6344 & 0.3813 & & 1.4283 & 0.7993 \\
\hline$\sigma_{v}$ & & 0.6312 & 0.6312 & & 0.6787 & 0.7718 \\
\hline$\sigma_{u} / \sigma_{v}$ & & 1.0050 & 0.6041 & & 2.1043 & 1.0356 \\
\hline
\end{tabular}




\begin{tabular}{|c|c|c|c|c|c|c|}
\hline \multirow[b]{2}{*}{ VARIABLES } & \multicolumn{3}{|c|}{ Half } & \multicolumn{3}{|c|}{ Half } \\
\hline & $\begin{array}{c}\text { OLS } \\
\text { Electricity }\end{array}$ & $\begin{array}{l}\text { Normal } \\
\text { Electricity }\end{array}$ & $\begin{array}{l}\text { Exponential } \\
\text { Electricity }\end{array}$ & $\begin{array}{l}\text { OLS } \\
\text { Fuel }\end{array}$ & $\begin{array}{l}\text { Normal } \\
\text { Fuel }\end{array}$ & $\begin{array}{c}\text { Exponential } \\
\text { Fuel }\end{array}$ \\
\hline $\ln Y$ & $0.568^{\star \star \star}$ & $0.569 * \star \star$ & $0.575^{\star \star \star}$ & $0.448^{\star \star \star}$ & $0.440 * \star \star$ & $0.431^{\star \star *}$ \\
\hline $\ln E m p$ & $0.503^{\star \star \star}$ & $0.499 * \star \star$ & $0.491^{\star \star *}$ & $0.476^{\star \star \star}$ & $0.462^{\star \star \star}$ & $0.472^{\star \star *}$ \\
\hline $\ln P_{E}$ & $-0.864^{\star \star \star}$ & $-0.888^{\star \star \star}$ & $-0.964^{\star \star \star}$ & 0.0506 & -0.0464 & -0.173 \\
\hline $\ln P_{F}$ & 0.0367 & 0.0404 & 0.0498 & $-0.752^{\star \star \star}$ & $-0.737^{\star \star \star}$ & $-0.721^{\star \star \star}$ \\
\hline $\ln H D D$ & $0.0946 * \star$ & $0.0916^{\star \star}$ & $0.0779 * \star$ & $0.203^{\star \star \star}$ & $0.192^{\star \star \star}$ & $0.175^{\star \star \star}$ \\
\hline $\ln C D D$ & $0.150 * \star \star$ & $0.155^{\star \star \star}$ & $0.144^{\star \star *}$ & 0.0498 & 0.0158 & -0.002 \\
\hline Constant & $-2.782^{\star \star *}$ & $-2.988^{\star \star \star}$ & $-2.901^{\star \star \star}$ & $1.868^{\star \star}$ & 0.326 & 0.651 \\
\hline $\ln \sigma_{u}^{2}$ & & $-0.908^{\star \star \star}$ & $-1.977^{\star \star \star}$ & & $0.479 * \star *$ & $-0.822^{\star * \star}$ \\
\hline $\ln \sigma_{v}^{2}$ & & $-1.032^{\star \star \star}$ & $-1.033^{\star \star \star}$ & & $-0.411^{* * *}$ & $-0.217^{\star \star}$ \\
\hline Returns to scale & 1.071 & 1.068 & 1.066 & 0.924 & 0.902 & 0.903 \\
\hline Observations & 2067 & 2067 & 2067 & 2067 & 2067 & 2067 \\
\hline R-squared & 0.866 & & & 0.639 & & \\
\hline Iteration Count & & 9 & 6 & & 7 & 6 \\
\hline $\begin{array}{c}* * * p<0.01, * * \\
p<0.05 \\
{ }^{*} p<0.1\end{array}$ & & & & & & \\
\hline mean efficiency & & $60 \%$ & $69 \%$ & & $36 \%$ & $52 \%$ \\
\hline median efficiency & & $65 \%$ & $77 \%$ & & $42 \%$ & $63 \%$ \\
\hline$\sigma_{u}$ & & 0.6376 & 0.3721 & & 1.2706 & 0.6629 \\
\hline$\sigma_{v}$ & & 0.5969 & 0.5966 & & 0.8142 & 0.8971 \\
\hline$\sigma_{u} / \sigma_{v}$ & & 1.0682 & 0.6237 & & 1.5604 & 0.7389 \\
\hline
\end{tabular}


November 18, 2016

Table 5 NAICS 336 Estimates for 2012

\begin{tabular}{|c|c|c|c|c|c|c|}
\hline VARIABLES & $\begin{array}{c}\text { OLS } \\
\text { Electricity }\end{array}$ & $\begin{array}{c}\text { Half } \\
\text { Normal } \\
\text { Electricity }\end{array}$ & $\begin{array}{l}\text { Exponential } \\
\text { Electricity }\end{array}$ & $\begin{array}{l}\text { OLS } \\
\text { Fuel }\end{array}$ & $\begin{array}{l}\text { Half Normal } \\
\text { Fuel }\end{array}$ & $\begin{array}{c}\text { Exponential } \\
\text { Fuel }\end{array}$ \\
\hline $\ln Y$ & $0.431^{* * *}$ & $0.423^{* * *}$ & $0.403^{* * *}$ & $0.277^{* * *}$ & $0.260 * * *$ & $0.240 * * *$ \\
\hline $\ln E m p$ & $0.588^{* * *}$ & $0.600^{* * *}$ & $0.631^{* * *}$ & $0.644^{* * *}$ & $0.659^{* * *}$ & $0.688^{* * *}$ \\
\hline $\ln P_{E}$ & $-1.039 * * *$ & $-1.027^{* * *}$ & $-0.999 * * *$ & $-0.248^{* * *}$ & $-0.237^{* * *}$ & $-0.229 * * *$ \\
\hline $\ln P_{F}$ & 0.00341 & -0.00252 & -0.0137 & $-0.813^{* * *}$ & $-0.799 * * *$ & $-0.801^{* * *}$ \\
\hline $\ln H D D$ & $0.0579 * * *$ & $0.0528^{* *}$ & $0.0471^{* *}$ & $0.162^{* * *}$ & $0.169^{* * *}$ & $0.170^{* * *}$ \\
\hline $\ln C D D$ & $0.0631^{* * *}$ & $0.0610^{* * *}$ & $0.0582^{* * *}$ & -0.0208 & -0.0126 & -0.0154 \\
\hline Constant & -0.585 & $-0.889 * *$ & $-0.598^{*}$ & $2.871^{* * *}$ & $2.109^{* * *}$ & $2.503^{* * *}$ \\
\hline $\ln \sigma_{u}^{2}$ & & $-1.121^{* * *}$ & $-2.001^{* * *}$ & & 0.178 & $-1.074 * * *$ \\
\hline $\ln \sigma_{v}^{2}$ & & $-0.782^{* * *}$ & $-0.849 * * *$ & & $-0.219^{* * *}$ & $-0.111^{* *}$ \\
\hline Returns to scale & 1.019 & 1.023 & 1.034 & 0.921 & 0.919 & 0.928 \\
\hline Observations & 4383 & 4383 & 4383 & 4383 & 4383 & 4383 \\
\hline R-squared & 0.866 & & & 0.671 & & \\
\hline Iteration Count & & 12 & 6 & & 7 & 6 \\
\hline $\begin{array}{c}* * * p<0.01,{ }^{* *} \\
p<0.05 \\
{ }^{*} p<0.1\end{array}$ & & & & & & \\
\hline mean efficiency & & $63 \%$ & $69 \%$ & & $42 \%$ & $56 \%$ \\
\hline median efficiency & & $68 \%$ & $78 \%$ & & $48 \%$ & $67 \%$ \\
\hline$\sigma_{u}$ & & 0.5712 & 0.3676 & & 1.0930 & 0.5844 \\
\hline$\sigma_{v}$ & & 0.6763 & 0.6540 & & 0.8962 & 0.9460 \\
\hline$\sigma_{u} / \sigma_{v}$ & & 0.8445 & 0.5621 & & 1.2195 & 0.6178 \\
\hline
\end{tabular}

In these results, total value of shipments is used in the model as measures of activity, $\ln Y$. Since labor is assumed to be sticky in the short run relative to energy use, $\operatorname{lnEmp}$ is treated as a quasi-fixed input relative to energy. It is unlikely that employment would adjust to differences in energy, since energy is a very small cost element in this sector. Labor can also control for some plant level utilization effects. The long run relationship between energy and plant scale is captured by the combined coefficient on production and labor, $\ln Y$ and $\operatorname{lnEmp}$. In a simple log-log specification the sum of the coefficients on $\operatorname{In} Y$ and InEmp reflect the economies of scale with respect to energy. If the sum of the coefficients is less than one then we can infer that larger plants will have lower energy intensity than smaller plants. This means that the model will control for scale differences with respect to energy use directly in the plant specific frontier so that differences in plant scale (size) will not be subsumed into the energy efficiency measure. Generally the RTS for electricity is close to unity or slightly larger, while for fuel it tends to be less than unity.

Own energy price elasticities range from -0.7 to -1.0 . With electricity tending to have slightly higher elasticity than fuel. This is higher than the energy price elasticity of -.47 estimated by (Bentzen 2004) using aggregate data for the U.S and higher than the aggregate energy price elasticities reported by 
(Parker and Liddle). However, the estimates estimated here are more in line with (Steinbuks and Neuhoff 2014) who use a KLEM cost function approach for OECD countries and estimate energy price elasticities for Electrical and optical equipment between -0.38 and -0.66 and for Basic metals and fabricated metal products between -0.86 and -1.06 . $^{9}$ These two industry categories are also closer to the MBD industries that are the focus of this study. As a cross section estimate, we would tend to interpret these as "long run" price elasticities, and would therefore expect them to be larger than short run elasticity estimates from panel data estimators.

One concern regarding the electricity results is possible endogeneity of prices, since plant level electric prices are used. This is not the case for fuel elasticities, because state level prices are used in the estimation. ${ }^{10}$ If large electricity users can negotiate better prices then this would likely bias our elasticity estimates upwards. Using both region and state level prices as an instrument for plant electric prices found no evidence of this type of endogeneity. ${ }^{11}$ This may be due to the relatively low share of energy cost to value added for these sectors. We also note that while cross price elasticities were not constrained to be equal, but are not significantly different from zero for NAICS 332 (Fabricated Metal Products) and 335 (Electrical Equip., Appliances, and Components). We have no a priori notions of electricity - fuel substitution in these sectors. On the other hand, the empirical pattern is for some statistically significant complementarity in 333,334 , and 336 , mostly in the fuel equation.

The weather effects are mostly as expected. HDD is large and significant in fuel use; CDD is not significant except in 332 (Fabricated Metal Products). Both CDD and HDD have significant impacts on electricity use in every NAICS but 334 (Computer and Electronic Products). Since electricity is used in both heating and cooling, this result is consistent with our apriori expectations of the impact of weather on energy use.

The R-squared from the OLS models suggest a better fit for electricity than fuel. This may be due to the reliance on imputed fuel use (i.e. cost of fuels divided by average natural gas price). By the same token the SFA analysis shows much higher levels of inefficiency in the fuel model, so it may simply be that there is more variation in fuel use relative to the production and climate variables in the estimated frontier. The Half normal specification of the frontier model attributes more variance to (in)efficiency than noise, when compared to the exponential specification in nine out of 10 fuel-NAICS equations; ${ }^{12}$ in one case the half normal model did not converge and the estimates are basically equivalent to OLS. This finding may simply be a statistical artifact of the alternative distributional assumptions for the inefficiency component. It is worth noting that the average efficiency estimates are generally similar across the half normal and exponential estimates in the electricity models. These average efficiency estimates differ by as little as 6 percentage points in the transportation equipment sector (NAICS 336), and are within nine percentage points of one another across the remaining sectors.

If we average across all five NAICS and model specifications the efficiency is shown below.

\footnotetext{
${ }^{9}$ The range reflects different modeling assumptions.

${ }^{10}$ Plant level fuel prices are only in the MECS and we are currently using CMF data. CMF data does allow us to compute plant prices.

${ }^{11}$ The instrumental variables analysis was done using 2-stage least squares, not SFA. We expect that a 2-stage control function in the SFA would have similar results.

${ }^{12}$ Based on computing the ratio of $\sigma_{u}$ to $\sigma_{v}$.
}

18| P a g e 
November 18, 2016

Table 6 Average Mean and Median Energy Efficiency across NAICS and SFA Models

\begin{tabular}{ccc} 
& Average electric efficiency & Average fuel efficiency \\
\hline Mean & $67 \%$ & $42 \%$ \\
Median & $73 \%$ & $51 \%$ \\
\hline
\end{tabular}

The mean and median efficiency estimates (based on the estimated error variances) range from a low of 32 percent (fuel use 334 - Computer and Electronic Products) to 86 percent (electricity use in 332 Fabricated Metal Products). The exponential model has higher efficiencies than half normal. Fuel efficiency is consistently worse than electric efficiency for all NAICS. The estimates across industries in electric vs fuel efficiency is remarkable similar, with the exception of electricity use in NAICS 332 . Recall that the half normal electricity frontier did not converge in this industry due in all likelihood to the fact that plants in this industry appear to be heavily clustered in closer proximity to the frontier. Plotting a kernel density for the plant level estimates of each type of energy efficiency, using the exponential model are shown in Figures 3 and 4.

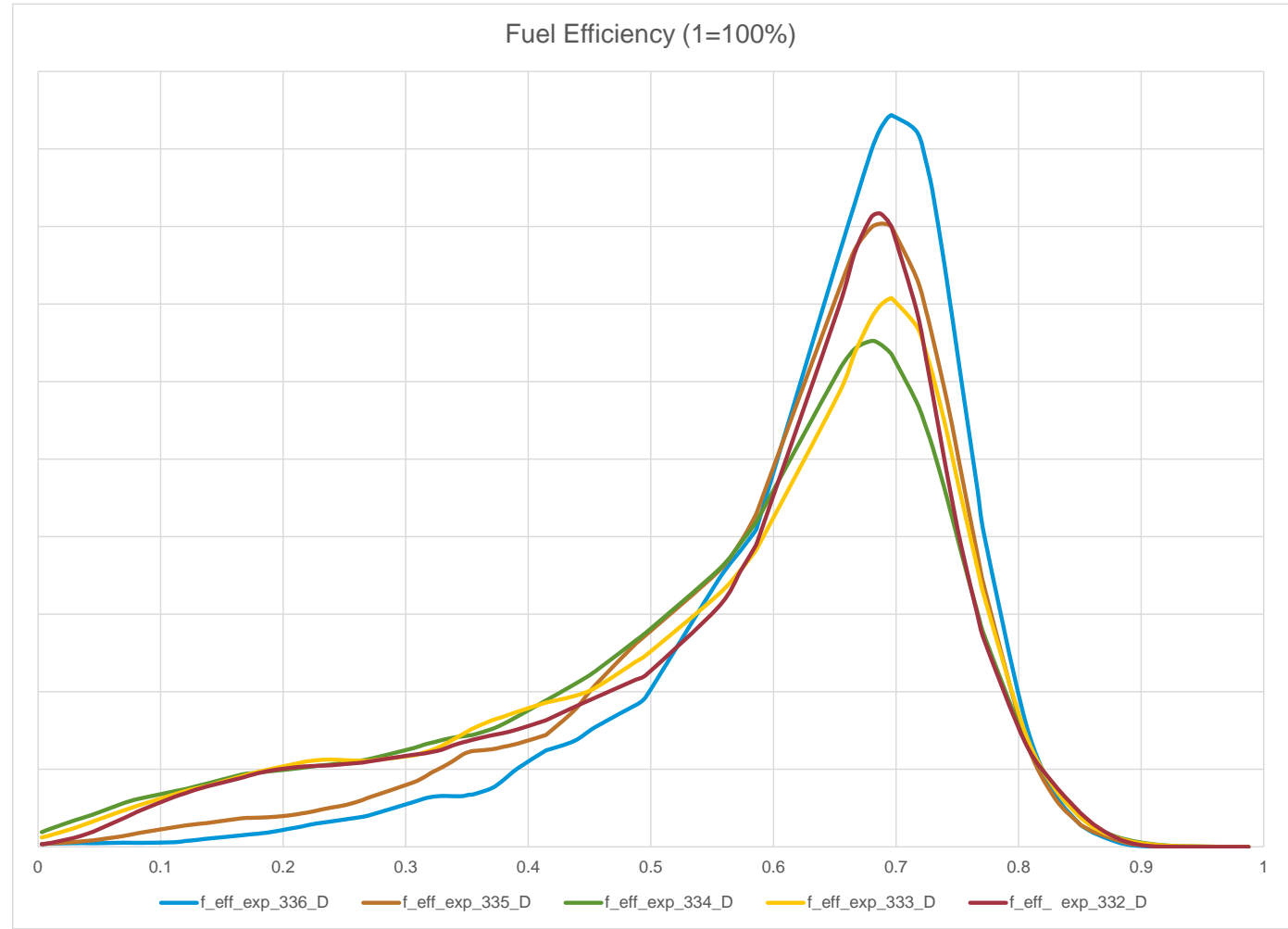

Figure 3 Kernel Density of Plant Level Fuel Efficiency Estimates by Industry (Year=2012, Exponential Distribution) 


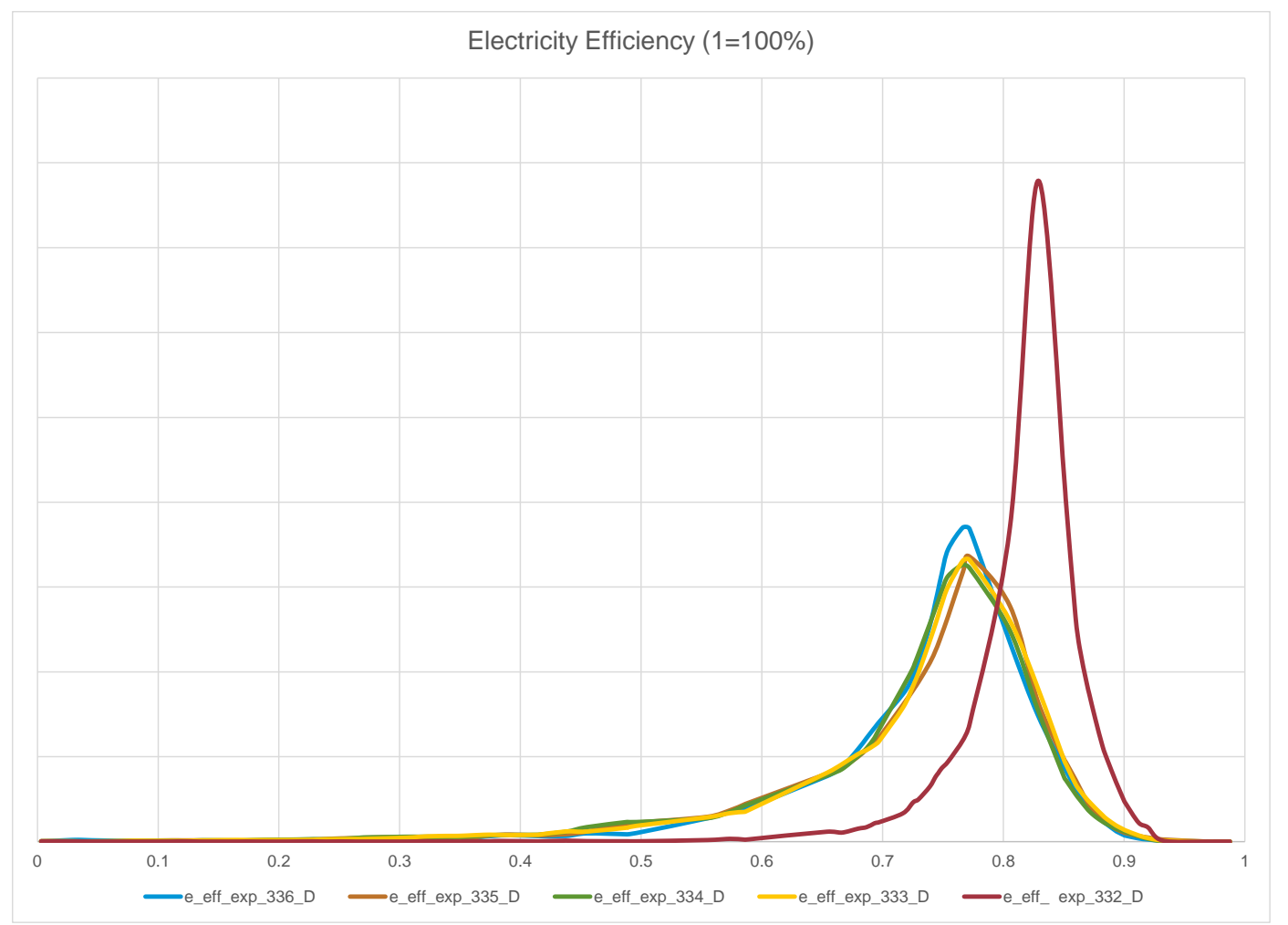

Figure 4 Kernel Density of Plant Level Electricity Efficiency Estimates by Industry (Year=2012, Exponential Distribution)

The kernel provided a non-parametric estimate of the efficiency distribution. For example, if we compute the median efficiency from the non-parametric kernel density and compare it to the parametric estimate of median efficiency in Tables 1-5 there is fairly close correspondence, but not perfect. Non-parametric median estimates of efficiency are between 1.5 and 3 percent higher for electricity. For Fuels it is 0.5 to 3 percent lower for all but NAICS 336 . However, one thing that is striking about the kernel density is that an extremely small number of plants have efficiency that exceed 90 percent. In fact, for fuel use only 2 percent of plants exceed 80 percent efficiency. This appears to be an artifact of the SFA analysis and the relatively high amount of noise vs efficiency in these model estimates.

\section{Malmquist Decomposition}

The Malmquist index and decomposition results presented below are based on the repeated cross sectional estimates, without regional or state effects, for each NAICS and year from 1992 through 2012. Many of the frontier models did not converge for 1987 so we begin the Malmquist analysis in 2002 relative to the prior year. Models for NIACS 334, 335, and 336 do not converge for the year 2007, so the 2012 index for those NAICS are computed relative to 2002, i.e., a ten year time step.

The formula for the Malmquist index requires the distance function to be able to be computed for each time period and evaluated at the plant data point for the current and prior time period. Since we estimate a separate frontier for each year, computing $D_{i}^{0}\left(y^{0}, x^{0}\right)$ and $D_{i}^{1}\left(y^{1}, x^{1}\right)$ is straightforward using the formula from equation $(\mathrm{X})$ above using the within year sample residuals.

$$
D_{i}^{t}\left(y^{t}, x^{t}\right)=E f f_{j, i, t}^{S F, m}=e^{\widehat{u_{j, l, t}}}
$$


Computing $D_{i}^{1}\left(y^{0}, x^{0}\right)$ and $D_{i}^{1}\left(y^{0}, x^{0}\right)$ is computed for each continuing plant by calculating the out of sample residuals and associate efficient measures for the adjacent years.

This is done for each NAICS and fuel types for every plant, using the repeated cross section exponential frontier estimates. We report a simple average of the three plant level indices, chained to $1992=1.0^{13}$. The average rates of growth over the entire 20 year time period is reported in Table 7 below. MI is the overall Malmquist index; ME is the Malmquist efficiency component; MT is the Malmquist technical change component. The overall rates of change for electricity are small; between $1 / 4$ and $3 / 4$ percent per annum. Most of this is due to technical change, but in 336 the declines in efficiency offsets the higher rate of technical change. In other words, the frontier is shifting but on average the industry is not keeping up with the frontier. For fuels, the average level of efficiency is lower and the rates of change are higher. In 333 and 334 efficiency improvements (catching up) increase overall rates of change while in 332, 335 and 336 the opposite is true. In all cases, technical change is large enough to have an overall positive impact.

In the two NAICS, 332 and 333, where we estimate frontiers for 2007 we see that there is a lot of volatility in the fuels component of the decomposition which is masked by the annual average growth rates (see Figure 5 and 6). In particular the technical change component is negative for both sectors. Recalling that our distance function is directional based on prices it is worth noting that fuel (natural gas) prices reached an all-time high in 2006 and were still very high in 2007. Given the estimated price elasticity we expect that the optimal fuel use would be lower in 2007 and hence be reflected as a shift (regress) in the frontier. So we don't interpret these results as an actual decline in technology, but rather as results of the short run volatility of natural gas prices, which by 2012 have returned to prior levels.

Table 7 Average annual growth rates from 1992-2012 for the plant level average Malmquist Indicies

\begin{tabular}{|c|ccc|ccc|}
\cline { 2 - 7 } \multicolumn{1}{c|}{} & \multicolumn{3}{c|}{ Electric growth rate } & \multicolumn{3}{c|}{ Fuel growth rate } \\
\hline \multirow{2}{*}{332 Fabricated Metal Products } & $\mathrm{MI}$ & $\mathrm{ME}$ & $\mathrm{MT}$ & $\mathrm{MI}$ & $\mathrm{ME}$ & $\mathrm{MT}$ \\
333 Machinery & $0.71 \%$ & $0.52 \%$ & $0.57 \%$ & $1.50 \%$ & $-0.33 \%$ & $2.83 \%$ \\
334 Computer and Electronic Products & $0.38 \%$ & $0.02 \%$ & $0.52 \%$ & $2.02 \%$ & $1.10 \%$ & $2.53 \%$ \\
335 Electrical Equip., Appliances, \& Component & $0.53 \%$ & $0.06 \%$ & $0.62 \%$ & $3.39 \%$ & $2.13 \%$ & $1.37 \%$ \\
336 Transportation equipment & $0.56 \%$ & $0.06 \%$ & $0.55 \%$ & $0.58 \%$ & $-0.76 \%$ & $1.43 \%$ \\
\hline
\end{tabular}

\footnotetext{
${ }^{13}$ Because of the way these indicies are computed the ME and MT rates do not sum to the MI rates.
} 
November 18, 2016

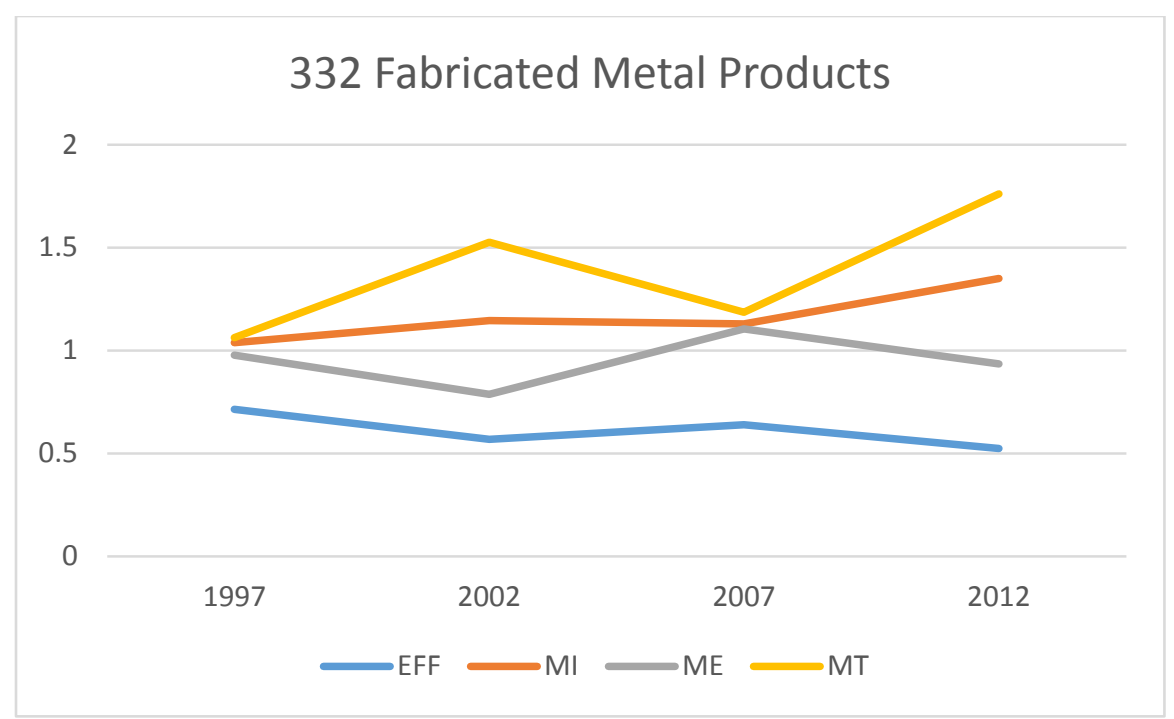

Figure 5 Malmquist Decomposition for NAICS 332

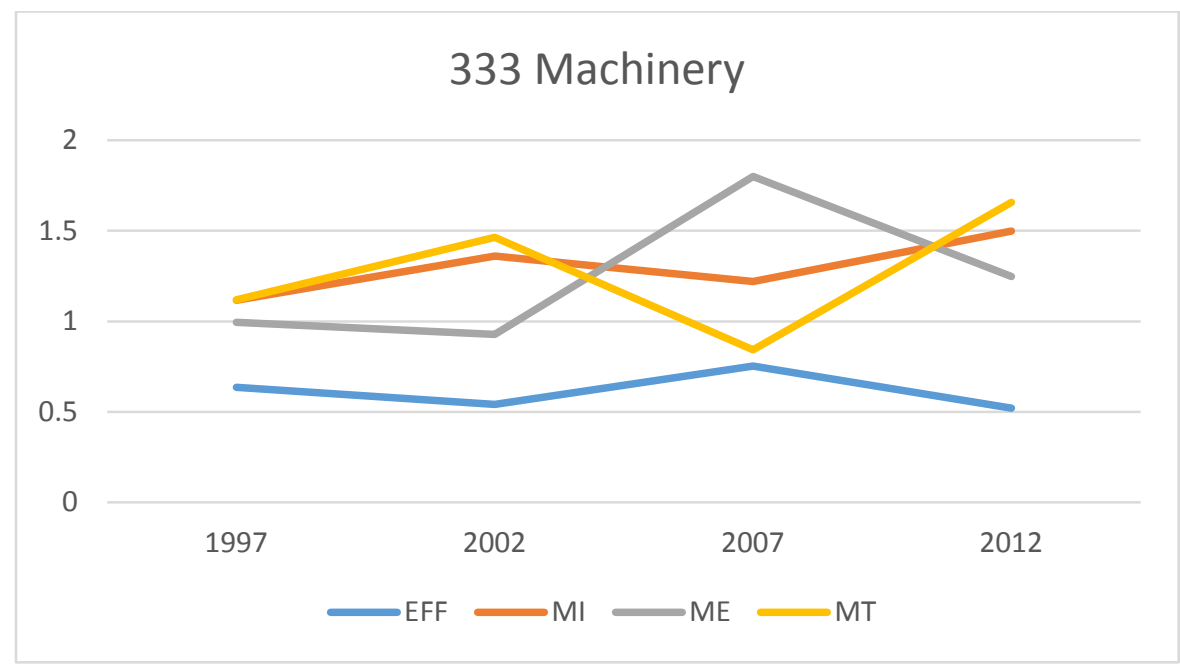

Figure 6 Malmquist Decomposition for NAICS 333

\section{New entrants}

The Malmquist index is only computed for continuing plants. In addition, there is a lot of turnover in these industries. Few plants exist for the entire 25 year time period and the great recession results in significant net exit between 2007 and 2012. One might expect that entrants would have newer technology and possibly be more efficient. To examine this we take each year for which we have a year specific frontier and compute the efficiency for entrants vs. continuing plants. We test to see if the mean efficiency is significantly different between these groups. The results are shown in Table 8 . While some differences are as small as 0.2 percent, most are statistically significant and the average entrant is more efficient than the average existing plant. The average difference over all the NAICS-year estimates is about 1 percent for electricity and 2 percent for fuels. 
November 18, 2016

Table 8 Efficiency of new vs existing plants (* indicates the new plants are have significantly higher efficiencies)

\begin{tabular}{|c|c|c|c|c|c|c|c|c|c|}
\hline & & \multicolumn{4}{|c|}{ Electricity Efficiency } & \multicolumn{4}{|c|}{ Fuel Efficiency } \\
\hline & & New & Existing & Difference & t-test & New & Existing & Difference & t-test \\
\hline \multirow[t]{4}{*}{332} & 1997 & $80.9 *$ & 80.7 & $0.2^{*}$ & 2.19 & $72.2^{*}$ & 71.4 & $0.8^{*}$ & 6.91 \\
\hline & 2002 & 72.3 & 72.0 & 0.2 & 1.59 & $57.9 *$ & 56.8 & $1.1^{*}$ & 4.89 \\
\hline & 2007 & $66.8^{*}$ & 66.1 & $0.6^{*}$ & 4.08 & $65.3^{*}$ & 64.0 & $1.3^{*}$ & 8.79 \\
\hline & 2012 & $80.4^{*}$ & 79.7 & $0.7^{*}$ & 8.57 & $53.6 *$ & 52.3 & $1.2^{*}$ & 4.96 \\
\hline \multirow[t]{4}{*}{333} & 1997 & 78.5 & 78.2 & 0.2 & 1.62 & $65.2^{*}$ & 63.6 & $1.7^{*}$ & 6.86 \\
\hline & 2002 & $70.4^{*}$ & 69.3 & $1.1^{*}$ & 4.22 & $57.3^{*}$ & 54.0 & $3.3^{*}$ & 9.25 \\
\hline & 2007 & $71.2^{*}$ & 70.5 & $0.7^{*}$ & 3.05 & 75.3 & 75.3 & 0.1 & 0.61 \\
\hline & 2012 & 70.6 & 70.5 & 0.1 & 0.36 & 52.1 & 52.1 & -0.1 & -0.16 \\
\hline \multirow[t]{4}{*}{334} & 1997 & $77.8^{*}$ & 77.1 & $0.7^{*}$ & 3.54 & $59.2^{*}$ & 57.0 & $2.2^{*}$ & 5.29 \\
\hline & 2002 & $69.8^{*}$ & 66.5 & $3.3^{*}$ & 8.26 & $54.7^{*}$ & 50.3 & $4.4^{*}$ & 7.87 \\
\hline & 2007 & - & - & - & - & - & - & - & - \\
\hline & 2012 & $70.4^{*}$ & 68.3 & $2.1^{*}$ & 4.56 & $51.7^{*}$ & 49.2 & $2.5^{*}$ & 3.58 \\
\hline \multirow[t]{4}{*}{335} & 1997 & 75.0 & 74.5 & 0.4 & 1.23 & 69.0* & 67.1 & 1.9* & 5.23 \\
\hline & 2002 & $76.8^{*}$ & 75.6 & $1.2^{*}$ & 3.61 & $62.1^{*}$ & 58.5 & $3.6^{*}$ & 6.55 \\
\hline & 2007 & - & - & - & - & - & - & - & - \\
\hline & 2012 & $71.3^{*}$ & 69.2 & $2.0^{*}$ & 3.82 & $56.2^{*}$ & 53.5 & $2.7^{*}$ & 3.71 \\
\hline \multirow[t]{4}{*}{336} & 1997 & $77.7^{*}$ & 77.2 & $0.6^{*}$ & 2.54 & $66.4^{*}$ & 64.2 & $2.1^{*}$ & 6.57 \\
\hline & 2002 & $70.4^{*}$ & 68.4 & $2.0^{*}$ & 5.53 & $62.7^{*}$ & 59.8 & $2.9 *$ & 7.48 \\
\hline & 2007 & - & - & - & - & - & - & - & - \\
\hline & 2012 & $70.7^{*}$ & 69.4 & $1.4^{*}$ & 3.84 & 59.0* & 57.1 & $1.9 *$ & 4.31 \\
\hline
\end{tabular}

\section{Pooled regression models}

Pooled models are used to explore year specific dummy variables as an alternative measure technical change. We set aside statistical concerns regarding the serial correlation of the plant level observations. Since the time steps are 5 -year it is possible that the correlation concerns are lessened. Since the cross sectional models that accommodate time series correlations fail to converge, this is the only way to econometrically explore the time series dimension. We also incorporate state and regional fixed effects in these pooled models. Interestingly, the pooled electric model for 332 and 333 do not converge without the region and state fixed effect, but converge easily with them. We also examine the impact of state and region level fixed effects on the parameter estimates.

The pooled models from 1987-2012 in five year time steps are shown in Tables 9-13. The first two columns are for electricity and fuels with year dummies and no region effects; the second pair of estimates include 4 Census region level dummies relative to the excluded region 4 ; the third pair of estimates include state fixed effects (coefficient are suppressed for Census disclosure purposes). 
The models with and without region and state fixed effects have similar output, labor, and price elasticities. There are a few changes in significance of the gas price in the electric equation when using state fixed effects, although sometimes the coefficient is larger and significant than the model without state effects and other times the reverse. The main coefficients that change are for climate, i.e., HDD and CDD, which are clearly location related characteristics. The HDD and CDD coefficients typically are smaller with region and state fixed effects; in a few cases the smaller coefficients for HDD in the electricity equations become insignificant, similarly for CDD and fuel use. In two cases (333 and 334) the CDD coefficient changes sign in the gas equation, and is statistically significant. A possible explanation is that there is heterogeneity in plant fuel use across different quantiles of CDDs and the state demeaned estimates are estimating the effects of CDD for plants with relatively similar climates.

Year effects are plotted in Figures 7-11. If we just consider electricity (shown in blue) then 332, 333, and 335 have generally downward (improving) electric trends. 334 showing some possible indications of electrification and 336 a exhibits a mixture. For fuels (shown in orange) we observe that 2007 is a unique year and highlight the Malmquist results that were suggested for two NAICS in the discussion above. It was a time of very high natural gas prices and also generally good economic conditions. Every sector has a positive year dummy for 2007. If we ignore 2007, then 332, 333, and 335 have generally downward (improving) fuel trends; and mixed results for 334 and 336 . The results for 334 and 336 are at odds with the Malmquist results based on the cross-sectional estimates. 
November 18, 2016

Table 9 NAICS 332 pooled model estimates

No region effects

Census Region Fixed Effects

State fixed effects

\begin{tabular}{|c|c|c|c|c|c|c|}
\hline Variable & Electric & Fuel & Electric & Fuel & Electric & Fuel \\
\hline Iny & $0.7774 * * *$ & $0.6687 * * *$ & $0.7704 * * *$ & $0.6682 * * *$ & $0.7704 * * *$ & $0.6680 * * *$ \\
\hline Inte & $0.3083^{* * *}$ & $0.2657 * * *$ & $0.3131^{* * *}$ & $0.2650 * * *$ & $0.3111 * * *$ & $0.2656 * * *$ \\
\hline Inep & $-0.7409 * * *$ & $-0.0160 *$ & $-0.6879 * * *$ & $-0.0249 * *$ & $-0.6346 * * *$ & -0.0161 \\
\hline Inngp & -0.0109 & $-0.8951 * * *$ & -0.018 & $-0.9573 * * *$ & $-0.1030 * * *$ & $-1.0031 * * *$ \\
\hline InHDD & $0.1028 * * *$ & $0.1239 * * *$ & $0.0475^{* * *}$ & $0.0360 * * *$ & $0.0308^{* * *}$ & $0.0248 *$ \\
\hline $\ln C D D$ & $0.0793 * * *$ & $0.0401 * * *$ & 0.0066 & -0.0046 & $0.0167^{* *}$ & -0.0029 \\
\hline yrdum2 & $-0.0238 * * *$ & $-0.0597 * * *$ & $-0.0738 * * *$ & $-0.0669 * * *$ & $-0.0822 * * *$ & $-0.0646 * * *$ \\
\hline yrdum3 & $-0.1278 * * *$ & $-0.1932 * * *$ & $-0.1619 * * *$ & $-0.1724 * * *$ & $-0.1558 * * *$ & $-0.1592 * * *$ \\
\hline yrdum4 & $-0.1711 * * *$ & $-0.3386 * * *$ & $-0.1894 * * *$ & $-0.2868 * * *$ & $-0.1652 * * *$ & $-0.2612^{* * *}$ \\
\hline yrdum5 & $-0.5325 * * *$ & -0.0165 & $-0.5753 * * *$ & $0.0831 * * *$ & $-0.4913 * * *$ & $0.1442 * * *$ \\
\hline yrdum6 & $-0.2447 * * *$ & $-0.3419 * * *$ & $-0.3038 * * *$ & $-0.2687 * * *$ & $-0.2819 * * *$ & $-0.2295 * * *$ \\
\hline regdum1 & & & $0.0462 * * *$ & $0.1835 * * *$ & & \\
\hline regdum2 & & & $0.0958 * * *$ & $0.1651^{* * *}$ & & \\
\hline regdum3 & & & $0.1292 * * *$ & $0.0886 * * *$ & & \\
\hline regdum4 & & & (omitted) & (omitted) & & \\
\hline State FE & No & No & No & No & Yes & Yes \\
\hline _cons & $-4.4485^{* * *}$ & $1.3866 * * *$ & $-3.5596 * * *$ & $2.3456 * * *$ & $-3.0548 * * *$ & $2.7675 * * *$ \\
\hline Usigma_cons & $-7.2562 * * *$ & $-1.6438 * * *$ & $-2.8853 * * *$ & $-1.6388 * * *$ & $-2.9064 * * *$ & $-1.6453^{* * *}$ \\
\hline Vsigma_cons & $-0.8417 * * *$ & $-0.5244 * * *$ & $-0.9199 * * *$ & $-0.5296 * * *$ & $-0.9239 * * *$ & $-0.5312 * * *$ \\
\hline Iterations & 100 & 8 & 8 & 6 & 9 & 6 \\
\hline & & legend: * & $\begin{array}{c}p<0.05 ; * * \\
p<0\end{array}$ & $\begin{array}{l}.01 ; * * * \\
p<0.001\end{array}$ & & \\
\hline
\end{tabular}


Table 10 NAICS 333 pooled model estimates

No region effects

Census Region Fixed Effects

State fixed effects

\begin{tabular}{|c|c|c|c|c|c|c|}
\hline \multirow{2}{*}{ Variable } & & & \\
\hline & Electric & Fuel & Electric & Fuel & Electric & Fuel \\
\hline Iny & $0.5565 * * *$ & $0.4935^{* * *}$ & $0.5559 * * *$ & $0.4936 * * *$ & $0.5573 * * *$ & $0.4935 * * *$ \\
\hline Inte & $0.4915^{* * *}$ & $0.3727^{* * *}$ & $0.4909 * * *$ & $0.3713^{* * *}$ & $0.4880 * * *$ & $0.3721 * * *$ \\
\hline Inep & $-0.7388 * * *$ & -0.0065 & $-0.7249 * * *$ & -0.0185 & $-0.7099 * * *$ & -0.0155 \\
\hline Inngp & -0.0172 & $-0.7731^{* * *}$ & -0.0117 & $-0.8427^{* * *}$ & $-0.1135 * * *$ & $-0.7946 * * *$ \\
\hline InHDD & $0.0532 * * *$ & $0.1688^{* * *}$ & $0.0346 * * *$ & $0.0598 * * *$ & 0.019 & 0.0178 \\
\hline $\ln C D D$ & $0.0777^{* * *}$ & $0.0386 * * *$ & $0.0440 * * *$ & -0.0112 & $0.0327^{* * *}$ & $-0.0358 * *$ \\
\hline yrdum2 & $0.0440 * * *$ & $-0.0866 * * *$ & $0.0227^{* *}$ & $-0.0975^{* * *}$ & $0.0197^{*}$ & $-0.1124 * * *$ \\
\hline yrdum3 & $-0.0950 * * *$ & $-0.2365^{* * *}$ & $-0.1105^{* * *}$ & $-0.2143 * * *$ & $-0.0878 * * *$ & $-0.2340 * * *$ \\
\hline yrdum4 & $-0.1073 * * *$ & $-0.4658 * * *$ & $-0.1143 * * *$ & $-0.4100 * * *$ & $-0.0611 * * *$ & $-0.4354 * * *$ \\
\hline yrdum5 & -0.0345 & $0.2230 * * *$ & $-0.0488^{*}$ & $0.3300 * * *$ & $0.0787^{* *}$ & $0.2659 * * *$ \\
\hline yrdum6 & $-0.0413^{*}$ & $-0.3776 * * *$ & $-0.0598 * *$ & $-0.3007^{* * *}$ & 0.0222 & $-0.3525 * * *$ \\
\hline regdum1 & & & $0.0589 * * *$ & $0.2268^{* * *}$ & & \\
\hline regdum2 & & & $0.0564 * * *$ & $0.1979 * * *$ & & \\
\hline regdum3 & & & $0.1054 * * *$ & $0.1133^{* * *}$ & & \\
\hline regdum4 & & & (omitted) & (omitted) & & \\
\hline State FE & No & No & No & No & Yes & Yes \\
\hline _cons & $-3.5958 * * *$ & $1.3069 * * *$ & $-3.2238 * * *$ & $2.4433 * * *$ & $-2.7318 * * *$ & $3.2491 * * *$ \\
\hline Usigma & $-2.4573 * * *$ & $-1.4177^{* * *}$ & $-2.4597 * * *$ & $-1.4122 * * *$ & $-2.4765 * * *$ & $-1.4117^{* * *}$ \\
\hline Vsigma & $-1.1463 * * *$ & $-0.6786 * * *$ & $-1.1476 * * *$ & $-0.6860 * * *$ & $-1.1520 * * *$ & $-0.6909 * * *$ \\
\hline Iterations & 6 & 6 & 7 & 6 & 6 & 7 \\
\hline & & legend: * & $\begin{array}{c}p<0.05 ; * * \\
p<0\end{array}$ & $\begin{array}{l}.01 ;{ }^{* * *} \\
p<0.001\end{array}$ & & \\
\hline
\end{tabular}


November 18, 2016

Table 11 NAICS 334 pooled model estimates

No region effects

Census Region Fixed Effects

State fixed effects

\begin{tabular}{|c|c|c|c|c|c|c|}
\hline \multirow[b]{2}{*}{ Variable } & & & \\
\hline & Electric & Fuel & Electric & Fuel & Electric & Fuel \\
\hline Iny & $0.3818^{* * *}$ & $0.2657 * * *$ & $0.3813 * * *$ & $0.2715^{* * *}$ & $0.3782 * * *$ & $0.2649 * * *$ \\
\hline Inte & $0.6521^{* * *}$ & $0.5472 * * *$ & $0.6528 * * *$ & $0.5418^{* * *}$ & $0.6563^{* * *}$ & $0.5490 * * *$ \\
\hline Inep & $-0.8041 * * *$ & $-0.1255^{* * *}$ & $-0.8038 * * *$ & $-0.1313^{* * *}$ & $-0.8400 * * *$ & $-0.1939 * * *$ \\
\hline Inngp & $0.2268 * * *$ & $-0.4795 * * *$ & $0.2258 * * *$ & $-0.5265 * * *$ & $0.2844^{* * *}$ & $-0.3998 * * *$ \\
\hline InHDD & -0.0143 & $0.1449 * * *$ & 0.0004 & $0.0663 * * *$ & 0.004 & $0.0700 *$ \\
\hline $\ln C D D$ & $0.0642^{* * *}$ & $0.0515^{* * *}$ & $0.0552 * * *$ & 0.0087 & $0.0372^{* *}$ & $-0.0486 * *$ \\
\hline yrdum2 & $0.1130 * * *$ & $0.0754 * * *$ & $0.1113^{* * *}$ & $0.0717^{* * *}$ & $0.1131^{* * *}$ & $0.0672^{* * *}$ \\
\hline yrdum3 & $0.1746^{* * *}$ & $0.0566^{* *}$ & $0.1742^{* * *}$ & $0.0720 * * *$ & $0.1698^{* * *}$ & $0.0552 * *$ \\
\hline yrdum4 & $0.1321 * * *$ & $-0.0925 * * *$ & $0.1331 * * *$ & $-0.0547^{*}$ & $0.1175^{* * *}$ & $-0.0912 * * *$ \\
\hline yrdum5 & $0.1635^{* * *}$ & $0.7734 * * *$ & $0.1645^{* * *}$ & $0.8422 * * *$ & $0.1130 * * *$ & $0.7227^{* * *}$ \\
\hline yrdum6 & $0.0752^{* * *}$ & 0.0427 & $0.0779 * * *$ & $0.0673^{* *}$ & $0.0743 * * *$ & $0.0526 *$ \\
\hline regdum1 & & & 0.0103 & $0.1760 * * *$ & & \\
\hline regdum2 & & & $-0.0523 * * *$ & $0.1141^{* * *}$ & & \\
\hline regdum3 & & & $0.0510 * * *$ & $0.0775 * * *$ & & \\
\hline regdum4 & & & (omitted) & (omitted) & & \\
\hline State FE & No & No & No & No & Yes & Yes \\
\hline _cons & $-2.6932 * * *$ & $1.2839 * * *$ & $-2.7491 * * *$ & $2.1511^{* * *}$ & $-3.2906 * * *$ & $1.9854 * * *$ \\
\hline Usigma & $-2.2867^{* * *}$ & $-1.1327^{* * *}$ & $-2.2853^{* * *}$ & $-1.1232^{* * *}$ & $-2.2997 * * *$ & $-1.1235^{* * *}$ \\
\hline Vsigma & $-0.8934 * * *$ & $-0.3631 * * *$ & $-0.8959 * * *$ & $-0.3706 * * *$ & $-0.8985^{* * *}$ & $-0.3791^{* * *}$ \\
\hline Iterations & 6 & 5 & 8 & 5 & 6 & 5 \\
\hline & & legend: * & $\begin{array}{c}\mathrm{p}<0.05 ; \\
\mathrm{p}<0\end{array}$ & $\begin{array}{l}.01 ; * * * \\
\mathrm{p}<0.001\end{array}$ & & \\
\hline
\end{tabular}


November 18, 2016

Table 12 NAICS 335 pooled model estimates

No region effects

Census Region Fixed Effects

State fixed effects

\begin{tabular}{|c|c|c|c|c|c|c|}
\hline \multirow[b]{2}{*}{ Variable } & & & \\
\hline & Electric & Fuel & Electric & Fuel & Electric & Fuel \\
\hline Iny & $0.5450 * * *$ & $0.4752 * * *$ & $0.5627 * * *$ & $0.4813 * * *$ & $0.5665 * * *$ & $0.4833 * * *$ \\
\hline Inte & $0.4969 * * *$ & $0.4040 * * *$ & $0.4821 * * *$ & $0.3980 * * *$ & $0.4773 * * *$ & $0.3959 * * *$ \\
\hline Inep & $-0.8523^{* * *}$ & $-0.1531 * * *$ & $-0.8670 * * *$ & $-0.2045^{* * *}$ & $-0.8869 * * *$ & $-0.2111 * * *$ \\
\hline Inngp & $0.1344 * * *$ & $-0.6642 * * *$ & $0.0793 * *$ & $-0.8588 * * *$ & -0.0173 & $-0.7981 * * *$ \\
\hline InHDD & $0.0398 * * *$ & $0.1886 * * *$ & 0.0247 & $0.0519 *$ & $0.0604^{*}$ & 0.0667 \\
\hline $\ln C D D$ & $0.1238^{* * *}$ & $0.0673^{* * *}$ & $0.0754^{* * *}$ & 0.0068 & $0.0596 * *$ & 0.0005 \\
\hline yrdum2 & $0.0582^{* * *}$ & $-0.1341 * * *$ & $0.0380 *$ & $-0.1204^{* * *}$ & $0.0455^{*}$ & $-0.1241 * * *$ \\
\hline yrdum3 & $-0.1013^{* * *}$ & $-0.2530 * * *$ & $-0.1117^{* * *}$ & $-0.1748 * * *$ & $-0.0768 * *$ & $-0.1922^{* * *}$ \\
\hline yrdum4 & $-0.1788 * * *$ & $-0.3997 * * *$ & $-0.1592 * * *$ & $-0.2503 * * *$ & $-0.0923 * *$ & $-0.2810 * * *$ \\
\hline yrdum5 & $-0.1162 * *$ & $0.2104 * * *$ & -0.0666 & $0.5057^{* * *}$ & 0.0767 & $0.4291^{* * *}$ \\
\hline yrdum6 & $-0.1372 * * *$ & $-0.2556 * * *$ & $-0.1086^{* *}$ & -0.0142 & 0.0179 & -0.067 \\
\hline regdum1 & & & $0.0842 * * *$ & $0.3965 * * *$ & & \\
\hline regdum2 & & & $-0.0528^{*}$ & $0.2048 * * *$ & & \\
\hline regdum3 & & & $0.0794 * * *$ & $0.1399 * * *$ & & \\
\hline & & & (omitted) & (omitted) & & \\
\hline State FE & No & No & No & No & Yes & Yes \\
\hline _cons & $-4.0363 * * *$ & 0.2412 & $-4.0097 * * *$ & $1.6043 * * *$ & $-3.7603^{* * *}$ & $2.2250^{* * *}$ \\
\hline Usigma & $-7.7733^{* * *}$ & $-2.0134^{* * *}$ & $-2.4580 * * *$ & $-1.9813^{* * *}$ & $-2.4491^{* * *}$ & $-1.9821 * * *$ \\
\hline Vsigma & $-1.0953^{* * *}$ & $-0.1726 * * *$ & $-0.9766^{* * *}$ & $-0.1896 * * *$ & $-0.9939 * * *$ & $-0.2004^{* * *}$ \\
\hline Iterations & 100 & 7 & 7 & 6 & 6 & 6 \\
\hline & & legend: * & $\begin{array}{c}\mathrm{p}<0.05 ; \\
\mathrm{p}<0\end{array}$ & $\begin{array}{l}.01 ; * * * \\
\mathrm{p}<0.001\end{array}$ & & \\
\hline
\end{tabular}


November 18, 2016

Table 13 NAICS 336 pooled model estimates

No region effects

Census Region Fixed Effects

State fixed effects

\begin{tabular}{|c|c|c|c|c|c|c|}
\hline Variable & Electric & Fuel & Electric & Fuel & Electric & Fuel \\
\hline Iny & $0.5145^{* * *}$ & $0.4269 * * *$ & $0.5135^{* * *}$ & $0.4270 * * *$ & $0.5063 * * *$ & $0.4237^{* * *}$ \\
\hline Inte & $0.5205^{* * *}$ & $0.4953^{* * *}$ & $0.5206^{* * *}$ & $0.4943 * * *$ & $0.5253 * * *$ & $0.4979 * * *$ \\
\hline Inep & $-0.8283^{* * *}$ & $-0.1644 * * *$ & $-0.8071 * * *$ & $-0.1837^{* * *}$ & $-0.8396 * * *$ & $-0.2053 * * *$ \\
\hline Inngp & $0.0687^{* * *}$ & $-0.6332 * * *$ & $0.0741^{* * *}$ & $-0.7575 * * *$ & 0.0073 & $-0.6234 * * *$ \\
\hline InHDD & $0.0431^{* * *}$ & $0.1353^{* * *}$ & $0.0193^{*}$ & $0.0465^{* * *}$ & 0.013 & 0.0169 \\
\hline $\operatorname{lnCDD}$ & $0.0685^{* * *}$ & 0.0165 & $0.0247^{* *}$ & -0.0151 & $0.0307^{*}$ & -0.035 \\
\hline yrdum2 & $0.1247 * * *$ & 0.0205 & $0.0997 * * *$ & 0.0291 & $0.1221^{* * *}$ & 0.0165 \\
\hline yrdum3 & $0.0355^{*}$ & $-0.1129 * * *$ & 0.0174 & $-0.0641 * *$ & $0.0608 * * *$ & $-0.1017^{* * *}$ \\
\hline yrdum4 & $-0.0574 * *$ & $-0.1636 * * *$ & $-0.0663 * * *$ & $-0.0707^{*}$ & -0.0023 & $-0.1391 * * *$ \\
\hline yrdum5 & $0.2806^{* * *}$ & $0.5172^{* * *}$ & $0.2614 * * *$ & $0.7084^{* * *}$ & $0.3854 * * *$ & $0.5402 * * *$ \\
\hline yrdum6 & $0.1923 * * *$ & -0.014 & $0.1654 * * *$ & $0.1188 * *$ & $0.2742^{* * *}$ & 0.0182 \\
\hline regdum1 & & & $0.0871 * * *$ & $0.2751^{* * *}$ & & \\
\hline regdum2 & & & $0.0831 * * *$ & $0.1898 * * *$ & & \\
\hline regdum3 & & & $0.1341 * * *$ & $0.0658 * *$ & & \\
\hline regdum4 & & & (omitted) & (omitted) & & \\
\hline $\begin{array}{l}\text { State FE } \\
\text { _cons }\end{array}$ & $\begin{array}{c}\text { No } \\
-3.9529 * * *\end{array}$ & $\begin{array}{c}\text { No } \\
1.4565^{* * *}\end{array}$ & $\begin{array}{c}\text { No } \\
-3.4598 * * *\end{array}$ & $\begin{array}{c}\text { No } \\
2.3497 * * *\end{array}$ & $\begin{array}{c}\text { Yes } \\
-3.4157^{* * *}\end{array}$ & $\begin{array}{c}\text { Yes } \\
2.4984^{* * *}\end{array}$ \\
\hline Usigma & $-2.4058 * * *$ & $-2.0090 * * *$ & $-2.4028 * * *$ & $-1.9830 * * *$ & $-2.4182^{* * *}$ & $-1.9678 * * *$ \\
\hline Vsigma & $-1.0146 * * *$ & $-0.2054 * * *$ & $-1.0189 * * *$ & $-0.2151 * * *$ & $-1.0291^{* * *}$ & $-0.2248 * * *$ \\
\hline \multirow[t]{2}{*}{ ic } & 7 & 6 & 7 & 6 & 6 & 6 \\
\hline & & legend: * & $\begin{array}{c}\mathrm{p}<0.05 ;{ }^{* *} \\
\mathrm{p}<0\end{array}$ & $\begin{array}{l}.01 ; * * * \\
\mathrm{p}<0.001\end{array}$ & & \\
\hline
\end{tabular}




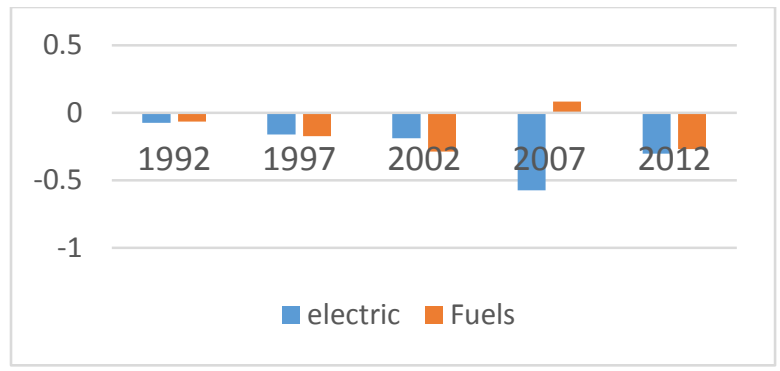

Figure 7 Year Fixed Effects for NAICS 332

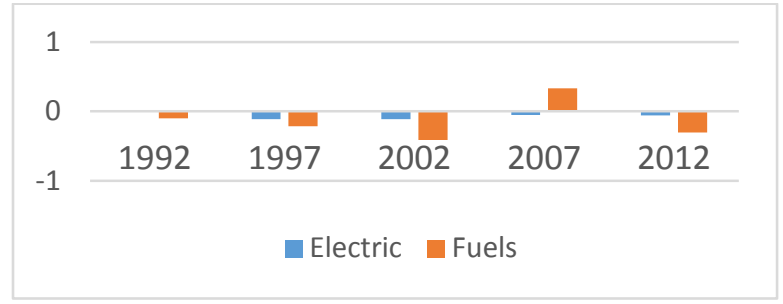

Figure 8 Year Fixed Effects for NAICS 333

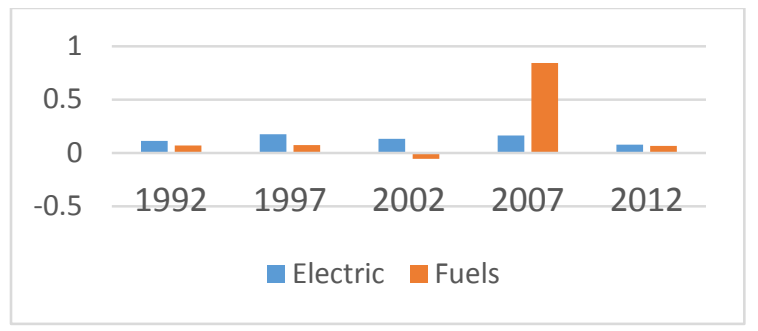

Figure 9 Year Fixed Effects for NAICS 334

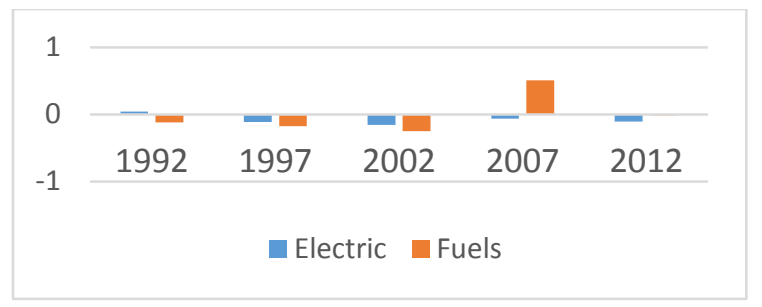

Figure 10 Year Fixed Effects for NAICS 335

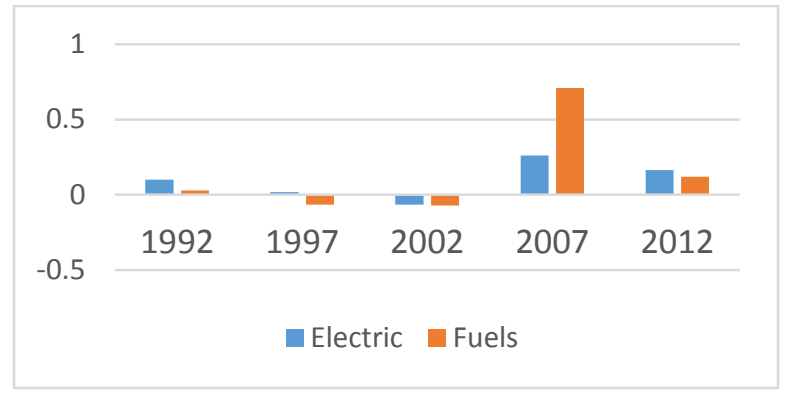

Figure 11 Year Fixed Effects for NAICS 336

30| P a g e 
November 18, 2016

\section{Conclusions}

\section{Summary}

This paper utilizes a rich plant level data source to estimate the evolution of energy efficiency in metal based durables over a 25 year period using a stochastic frontier regression analysis approach applied to an ad-hoc energy demand framework. We apply the analysis to 53 digit NAICS in the MBD manufacturing industries. We control for 6-digit NAICS, location based climate, and energy prices to estimate frontier demand and the distribution of efficiency relative to the frontier in 5-year time steps from the quinquennial EC.

We find that median efficiency for electricity is higher (78 percent) than for fuel use (62 percent) averaged across all five sectors. The Malmquist decomposition implies modest overall improvements in electricity efficiency over time, ranging from 0.2 to 0.7 percent annually; overall fuel performance improved at a faster rate, from 0.5 to 3.4 percent. In both cases, most of this improvement is from technical change, i.e. shifts in the frontier. However, for NAICS 332 and 335 failure of plants "keeping up," as measured by the Malmquist efficiency index, retarded the overall improvement in fuel use on those sectors. The failure to "keep up" eroded gains in both electricity and fuel use in NIACS 336.

\section{Caveats and Future work}

One possible variation on the SFA models applies to the electricity equations. One could use state average electricity prices from SEDS in the frontier, assuming that that is frontier behavior is determined by a more aggregate price level, but that the variance of distribution of efficiency in the half-normal model is not constant, but heteroscedastic and depends on the plant level price.

$$
\sigma_{u_{j}}=\exp \left(\alpha+\gamma P_{t, i}^{E_{j}}\right)
$$

Assuming the coefficient $\gamma$ is negative this would imply that plants with higher prices tend to be closer to the (state electricity price determined) coefficient. Other variables could be added to this heteroscedastic model. One possibility is a state fixed effect or some policy variable.

\section{Using the SFA results in NEMS}

This research is not intended to be a wholesale replacement of the NEMS structure. However, the choice of 3-digit pooled NAICS with detailed 6-digit industry controls is a decision based on the NEMS forecasting environment, not research issues per se. By the same token, 3-digit NAICS (2-digit SIC) is a common choice of aggregation in the energy literature so it is fairly natural one to make. We have not fully examined how best to make use of the proposed SFA approach within the NEMS forecasting environment, but rather focus the analysis to develop a set of estimates of energy efficiency in MBD that can be used by EIA to inform changes in the NEMS parameters. The underlying efficiency distributions should be more than adequate to develop "simple" NEMS efficiency scenarios, e.g. assuming the lower quartile moves to the median, etc.

The separation of process and building energy in NEMS is not something that this approach readily supports. The plant level data are for the entire establishment and therefore the model incorporates building and process energy. This is one motivation to attempt to control for weather/climate in the form of plant specific HDD and CDD. We presume that EIA would either have to assume that the 
efficiency distributions that are estimated apply equally to process and building energy or develop some ex-post method to reconcile the total energy efficiency distribution with a separate distribution of building energy efficiency.

The kernel density estimated of the efficiency distributions provide a basis for a variety of efficiency related scenario analysis. For example, one could envision a scenario where the lowest performing plans (e.g. lowest quartile) improve to some target level (e.g. $2^{\text {nd }}$ or $3^{\text {rd }}$ quartile). The fact that few plants have efficiency exceeding 90 percent suggests that scenarios of this type might be more "realistic" compared to ones that assume 100, or even 90, percent efficiency targets. In essence, 100 percent efficiency may be achievable, but rarely in practice.

\section{REFERENCES}

Adetutu, M. O., A. J. Glass and T. G. Weyman-Jones (2016). "Economy-wide Estimates of Rebound Effects: Evidence from Panel Data." The Energy Journal 37(3): 251-269.

Allcott, H. and M. Greenstone (2012). "Is There an Energy Efficiency Gap?" Journal of Economic Perspectives 26(1): 3-28.

Aranda-Usón, A., G. Ferreira, M. D. Mainar-Toledo, S. Scarpellini and E. Llera Sastresa (2012). "Energy consumption analysis of Spanish food and drink, textile, chemical and non-metallic mineral products sectors." Energy 42(1): 477-485.

Bartelsman, E. and W. Gray (1996). "The NBER Manufacturing Productivity Database." Technical Working Paper 205, National Bureau of Economic Research, Cambridge MA.

Bentzen, J. (2004). "Estimating the rebound effect in US manufacturing energy consumption." Energy Economics 26(1): 123-134.

Boyd, G., E. Dutrow and W. Tunnesen (2008). "The Evolution of the Energy Star Industrial Energy Performance Indicator for Benchmarking Plant Level Manufacturing Energy Use." Journal of Cleaner Production 16(6): 709-715.

Boyd, G., S. Karlson, M. Neifer and M. Ross (1993). "Energy Intensity Improvements in Steel Minimills." Contemporary Policy Issues 11(3): 88-99.

Boyd, G. and J. Pang (2000). " Estimating the Linkage between Energy Efficiency and Productivity." Energy Policy 28(5): 289-296.

Boyd, G. and G. Zhang (2013). "Measuring improvement in energy efficiency of the US cement industry with the ENERGY STAR Energy Performance Indicator." Energy Efficiency 6(1): 105-116.

Boyd, G. A. (2005). "A Method for Measuring the Efficiency Gap between Average and Best Practice Energy Use: The ENERGY STAR Industrial Energy Performance Indicator." Journal of Industrial Ecology 9(3): 51-65.

Boyd, G. A. (2008). "Estimating Plant Level Manufacturing Energy Efficiency with Stochastic Frontier Regression." The Energy Journal 29(2): 23-44.

Boyd, G. A. (2014). "Estimating the changes in the distribution of energy efficiency in the U.S. automobile assembly industry." Energy Economics 42: 81-87.

Boyd, G. A. (2016). "Comparing the statistical distributions of energy efficiency in manufacturing: metaanalysis of 24 Case studies to develop industry-specific energy performance indicators (EPI)." Energy Efficiency: doi:10.1007/s12053-016-9450-y (link.springer.com/article/10.1007/s12053-0169450-y/fulltext.html).

Boyd, G. A. and E. M. Curtis (2014). "Evidence of an "Energy-Management Gap" in U.S. manufacturing: Spillovers from firm management practices to energy efficiency." Journal of Environmental Economics and Management 68(3): 463-479. 
Coelli, T. J., D. S. P. Rao, C. J. O'Donnell and G. E. Battese (2005). An Introduction to Efficiency and Productivity Analysis. New York: Springer US.

Davis, S. J., C. Grim, J. Haltiwanger and M. Streitwieser (2012). "Electricity Unit Value Prices and Purchase Quantities: U.S. Manufacturing Plants, 1963-2000." Review of Economics and Statistics 95(4): 1150-1165.

Energy Information Administration (2014). Model Documentation Report: Industrial Demand Module of the National Energy Modeling System. Washington DC, U.S. Department of Energy.

Färe, R. and S. Grosskopf (1992). "Malmquist Productivity Indexes and Fisher Ideal Indexes." The Economic Journal 102(410): 158-160.

Feijoó, M. a. L., J. F. Franco and J. M. Hernández (2002). "Global warming and the energy efficiency of Spanish industry." Energy Economics 24(4): 405-423.

Ferrier, G. D. and J. G. Hirschberg (1992). "Climate Control Efficiency." The Energy Journal 13(1): 37-54.

Filippini, M. and L. C. Hunt (2011). "Energy Demand and Energy Efficiency in the OECD Countries: A Stochastic Demand Frontier Approach." The Energy Journal 32(2): 59-80.

Filippini, M. and L. C. Hunt (2012). "US residential energy demand and energy efficiency: A stochastic demand frontier approach." Energy Economics 34(5): 1484-1491.

Filippini, M. and L. C. Hunt (2015). "Measurement of energy efficiency based on economic foundations." Energy Economics 52, Supplement 1: S5-S16.

Gately, D. and H. G. Huntington (2002). "The asymmetric effects of changes in price and income on energy and oil demand." The Energy Journal 23(1): 19-56.

Greene, W. H. (2005). Fixed and Random Effects in Stochastic Frontier Models. Journal of Productivity Analysis. 23(1): 7-32.

Huntington, H. (1995). "Been Top Down So Long It Looks Like Bottom Up." Energy Policy 22(10): 833839.

Jaffe, A. B. and R. N. Stavins (1994). "The energy-efficiency gap What does it mean?" Energy Policy 22(10): 804-810.

Lin, B. and H. Long (2015). "A stochastic frontier analysis of energy efficiency of China's chemical industry." Journal of Cleaner Production 87: 235-244.

Lundgren, T., P.O. Marklund and S. Zhang (2016). "Industrial energy demand and energy efficiency Evidence from Sweden." Resource and Energy Economics 43: 130-152.

Mukherjee, K. (2008). "Energy use efficiency in U.S. manufacturing: A nonparametric analysis." Energy Economics 30(1): 76-96.

Murillo-Zamorano, L. (2004). "Economic efficiency and frontier techniques." Journal of Economic Surveys 18(1): 33-77.

Parker, S. and B. Liddle "Energy Efficiency in the Manufacturing Sector of the OECD: Analysis of price elasticities." Energy Economics 58:38-45.

Steinbuks, J. and K. Neuhoff (2014). "Assessing energy price induced improvements in efficiency of capital in OECD manufacturing industries." Journal of Environmental Economics and Management 68(2): 340-356.

Zhang, S., T. Lundgren and W. Zhou (2016). "Energy efficiency in Swedish industry: A firm-level data envelopment analysis." Energy Economics 55: 42-51.

Zhou, P., B. W. Ang and K. L. Poh (2008). "A survey of data envelopment analysis in energy and environmental studies." European Journal of Operational Research 189(1): 1-18.

Zhou, P., B. W. Ang and D. Q. Zhou (2012). "Measuring economy-wide energy efficiency performance: A parametric frontier approach." Applied Energy 90(1): 196-200. 